Review

\title{
Six-Membered Aromatic Polyazides: Synthesis and Application
}

\author{
Sergei V. Chapyshev
}

Institute of Problems of Chemical Physics, Russian Academy of Sciences, Chernogolovka 142432, Moscow Region, Russian; E-Mail: s.chapyshev@mail.ru; Tel.: +7-4965-223-507

Academic Editor: Klaus Banert

Received: 11 September 2015 / Accepted: 13 October 2015 / Published: 21 October 2015

\begin{abstract}
Aromatic polyazides are widely used as starting materials in organic synthesis and photochemical studies, as well as photoresists in microelectronics and as cross-linking agents in polymer chemistry. Some aromatic polyazides possess high antitumor activity, while many others are of considerable interest as high-energy materials and precursors of high-spin nitrenes and $\mathrm{C}_{3} \mathrm{~N}_{4}$ carbon nitride nanomaterials. The use of aromatic polyazides in click-reactions may be a new promising direction in the design of various supramolecular systems possessing interesting chemical, physical and biological properties. This review is devoted to the synthesis, properties and applications of six-membered aromatic compounds containing three and more azido groups in the ring.
\end{abstract}

Keywords: polyazides; high-energy materials; high-spin nitrenes; cross-linking agents; photoresists; click-reactions

\section{Introduction}

To date, just about two dozen six-membered aromatic compounds containing three and more azido groups in the ring are known. Nevertheless, investigations of these polyazides have played an important role in the development of chemistry. Thus, the first data on the linear structure of the azido groups were obtained due to X-ray diffraction studies of crystalline 2,4,6-triazido-1,3,5-triazine [1-5]. The thermal and detonative decomposition of this triazide allowed as well the first preparation of diverse $\mathrm{C}_{3} \mathrm{~N}_{4}$ carbon nitride nanomaterials and carbon nanotubes [6-9]. The first organic septet hexaradical was prepared by the photolysis of 1,3,5-triazido-2,4,6-tricyanobenzene [10]. Later, a great variety of high-spin nitrenes possessing unusual magnetic characteristics were obtained by the photolysis of various 1,3,5-triazidobenzenes, 2,4,6-triazidopyridines, 2,4,6-triazidopyrimidines and 2,4,6-triazido-1,3,5-triazine [11-33]. These studies 
of high-spin nitrenes opened up new prospects in design of new organic magnetic materials and provided important information about UV-vis, IR and EPR spectra of organic molecules with the ground quintet and septet spin-state. In particular, it was found that the placement of heavy bromine atoms in molecules of high-spin nitrenes can strengthen several times the magnetic properties of organic polyradicals [26,33]. Six-membered aromatic triazides have also played an important role in investigations of the reactivity of the azido groups. Thus, it was found that the more electron-deficient $\gamma$-azido groups of 2,4,6-triazidopyridines selectively react with electron-rich dipolarophiles, phosphines, phosphites and reductants [34,35]. By contrast, the more electron-rich $\alpha$-azido groups of the same triazides are the most reactive toward electron-poor dipolarophiles. Since 2002, organic azides are widely used as starting materials in the copper-catalyzed azide-alkyne cycloadditions or so-called click-reactions to prepare organic compounds with interesting chemical, physical and biological properties [36,37]. Recent examples on the use of aromatic diazides in such reactions demonstrate a huge synthetic potential of aromatic polyazides in design of new polyfunctional organic materials [38-60]. The present review provides concise and precise updates on the latest progress in the synthesis and investigation of six-membered aromatic polyazides made by July 2015 .

\section{Cyanuric Triazide}

2,4,6-Triazido-1,3,5-triazine or cyanuric triazide (1) was prepared for the first time by H. Finger in 1907, using diazotization of tris-hydrazine 2 with $\mathrm{NaNO}_{2}$ in acidic media (Scheme 1) [61]. Several years later, a more convenient way to prepare $\mathbf{1}$ based on triazidation of cyanuric chloride $\mathbf{3}$ with sodium azide in aqueous acetone was developed by Ott and Ohse [62]. Currently, triazide 1 is readily prepared in almost quantitative yield by addition of small portions of solid sodium azide to solutions of chloride $\mathbf{3}$ in acetone at room temperature $[63,64]$. On crystallization from ethanol, triazide $\mathbf{1}$ forms dense colorless crystals with a melting point of $94{ }^{\circ} \mathrm{C}$ [61-64]. Due to its high nitrogen content $(82.35 \%)$, triazide 1 is very sensitive to impact, friction and electrostatic discharge. On working with it, one should always handle 1 only with plastic spatulas and use thick gloves behind a blast shield.

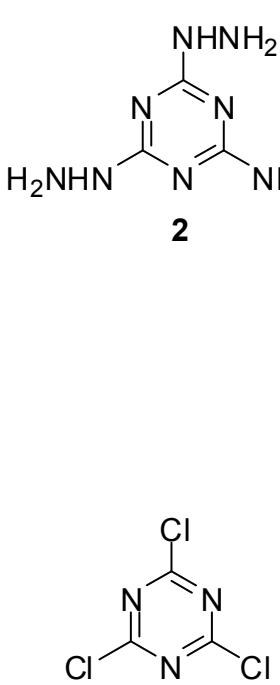

3
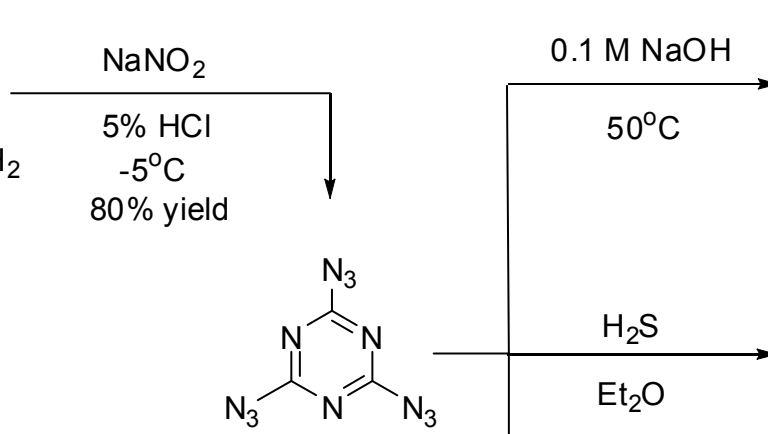

1

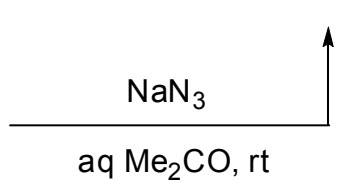

$90 \%$ yield<smiles>Oc1nc(O)nc(O)n1</smiles><smiles>Nc1nc(N)nc(N)n1</smiles>

5<smiles>Nc1nc(N)nc(N)n1</smiles>

6

Scheme 1. Synthesis and some transformations of triazide 1. 
Early studies have shown that triazide 1 was quickly hydrolyzed to cyanuric acid (4) on heating in $0.1 \mathrm{M}$ solutions of sodium hydroxide at $50{ }^{\circ} \mathrm{C}$ (Scheme 2) [62]. By action of gaseous hydrogen sulfide, triazide 1 was reduced to melamine (5) [65]. Similar reaction of 1 with gaseous ammonia afforded aminodiazide 6 in almost quantitative yield [65]. In the last case, the reaction can formally be considered as nucleophilic substitution reaction of the azido group in $\mathbf{1}$ for the amino group. Thus, this triazide reacts in the same manner with various alkyl amines to give aminodiazides $7 \mathbf{a}-\mathbf{n}$ in high yields [66]. All diazides 5 and 7a-n present as white solids with a melting point ranging from $44{ }^{\circ} \mathrm{C}$ for $7 \mathbf{c}$ till $200{ }^{\circ} \mathrm{C}$ for $\mathbf{6}$ and are almost insensitive to impact, friction and electrostatic discharge. These compounds may be of practical interest as insensitive high-energy additives and reactants for click-reactions. The reduction of triazide 1 with hydridoplatinum complex $\left(\mathrm{Et}_{3} \mathrm{P}\right)_{2} \mathrm{Pt}(\mathrm{Cl}) \mathrm{H}$ gives air-stable amidoplatinum complex 8 in $100 \%$ yield (Scheme 2) [67]. The latter can be considered as an analog of aminodiazides $\mathbf{6}$ and $\mathbf{7 a}-\mathbf{n}$.

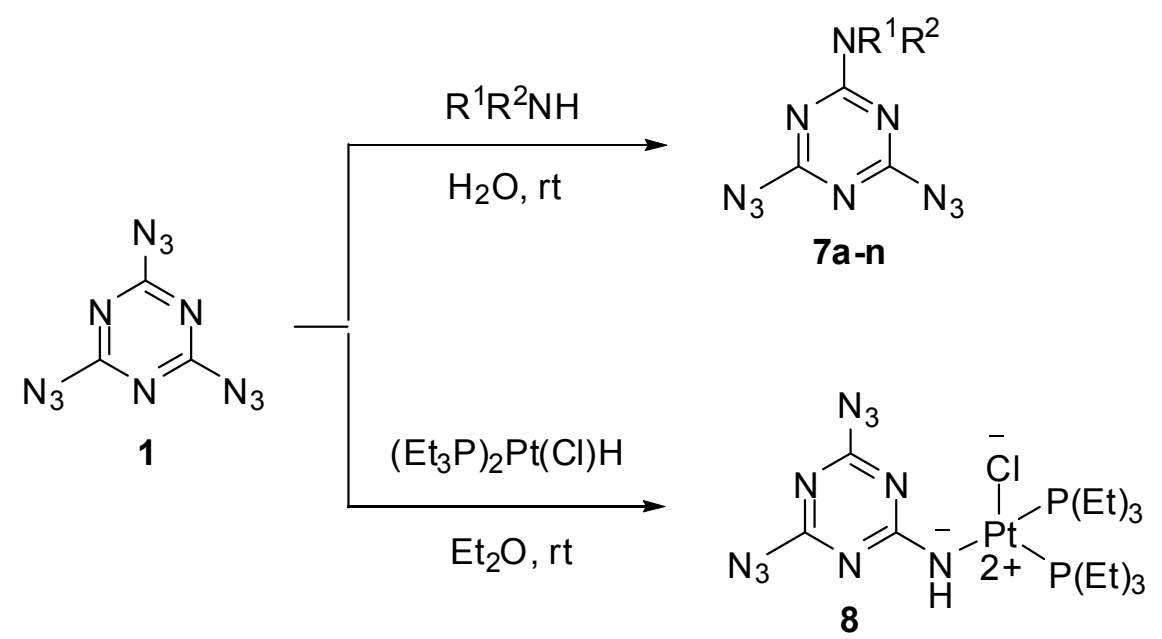

\footnotetext{
$\mathrm{R}^{1} \mathrm{R}^{2} \mathrm{~N}-=\mathbf{a}: \mathrm{MeHN}-, \mathbf{b}:$ EtHN-, c: $\mathrm{Me}_{2} \mathrm{~N}-, \mathbf{d}: \operatorname{PrHN}-, \mathbf{e}: i-\mathrm{PrHN}-, \mathbf{f}: \mathrm{BuHN}-, \mathbf{g}: i-\mathrm{BuHN}-$, h: $t$-BuHN-, i: $\mathrm{CH}_{2}: \mathrm{CHCH}_{2} \mathrm{HN}-$, j: $n-\mathrm{HexHN}-, \mathbf{k}: \mathrm{MeOCH}_{2} \mathrm{CH}_{2} \mathrm{HN}-$, I: $\mathrm{MeO}\left(\mathrm{CH}_{2}\right)_{3} \mathrm{HN}-, \mathbf{m}$ : cyclohexylamino, $\mathbf{n}$ : morpholino
}

Scheme 2. Reactions of triazide 1 with alkyl amines and $\left(\mathrm{Et}_{3} \mathrm{P}\right)_{2} \mathrm{Pt}(\mathrm{Cl}) \mathrm{H}$.

All three azido groups of 1 react with Grignard reagents to give tris-triazenes $9 a-\mathbf{d}$ in $47 \%-70 \%$ yield (Scheme 3) [68]. Triazenes are of considerable interest as anticancer drugs and powerful carcinogens [69-71].

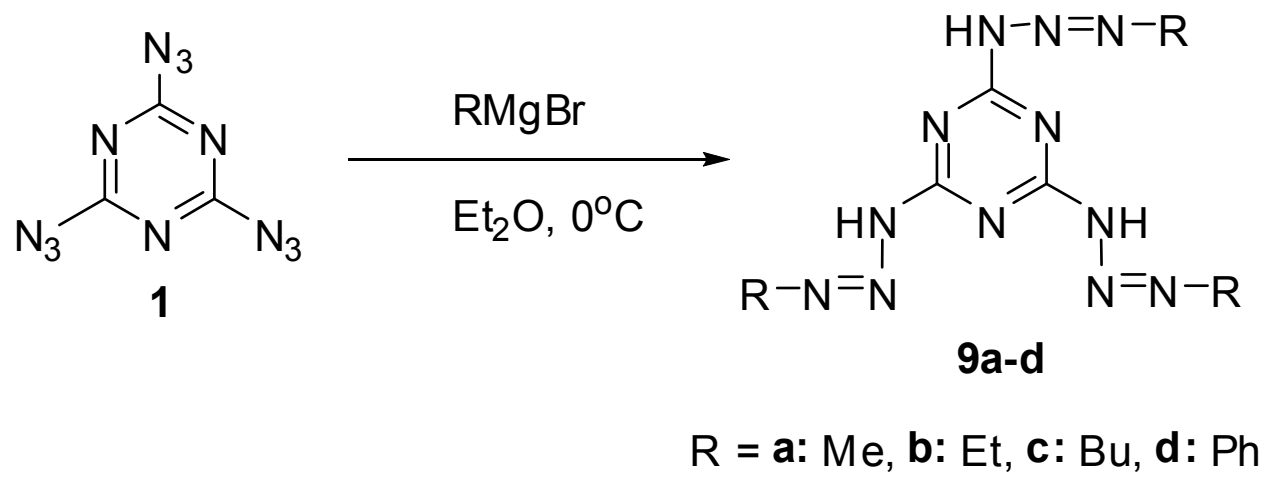

Scheme 3. Reactions of triazide 1 with Grignard reagents. 
The first attempt to investigate the Staudinger-Meyer reaction of triazide 1 was undertaken by Kesting in 1923 [72]. The reaction of this triazide with an excess of triphenylphosphine in ether gave a single product that was assigned to azide 12, based on the elemental analysis data (Scheme 4). However, recent studies showed that this product really corresponds to tetrazole $\mathbf{1 3}[63,64]$. The first stage of the reaction involves the formation of diazide $\mathbf{1 0}$ that exists in organic solutions in equilibrium with azidotetrazole 11. The ratio of $\mathbf{1 0}$ to $\mathbf{1 1}$ in chloroform and dimethylsulfoxide solutions is $\sim 1: 3$ and 1:50, respectively [64]. The addition of two equivalents of triphenylphosphine to triazide 1 gives tetrazole $\mathbf{1 3}$ as a single product. The structures of tetrazoles 11 and 13 were unambiguously proved by using ${ }^{13} \mathrm{C}-,{ }^{15} \mathrm{~N}$ - and ${ }^{31} \mathrm{P}-\mathrm{NMR}$ spectroscopy and $\mathrm{X}$-ray diffraction analysis $[63,64]$. Tetrazole 13 does not react with triphenylphosphine in solution. The tris-adduct 14 can only be obtained by melting 13 with an excess of triphenylphosphine [64].

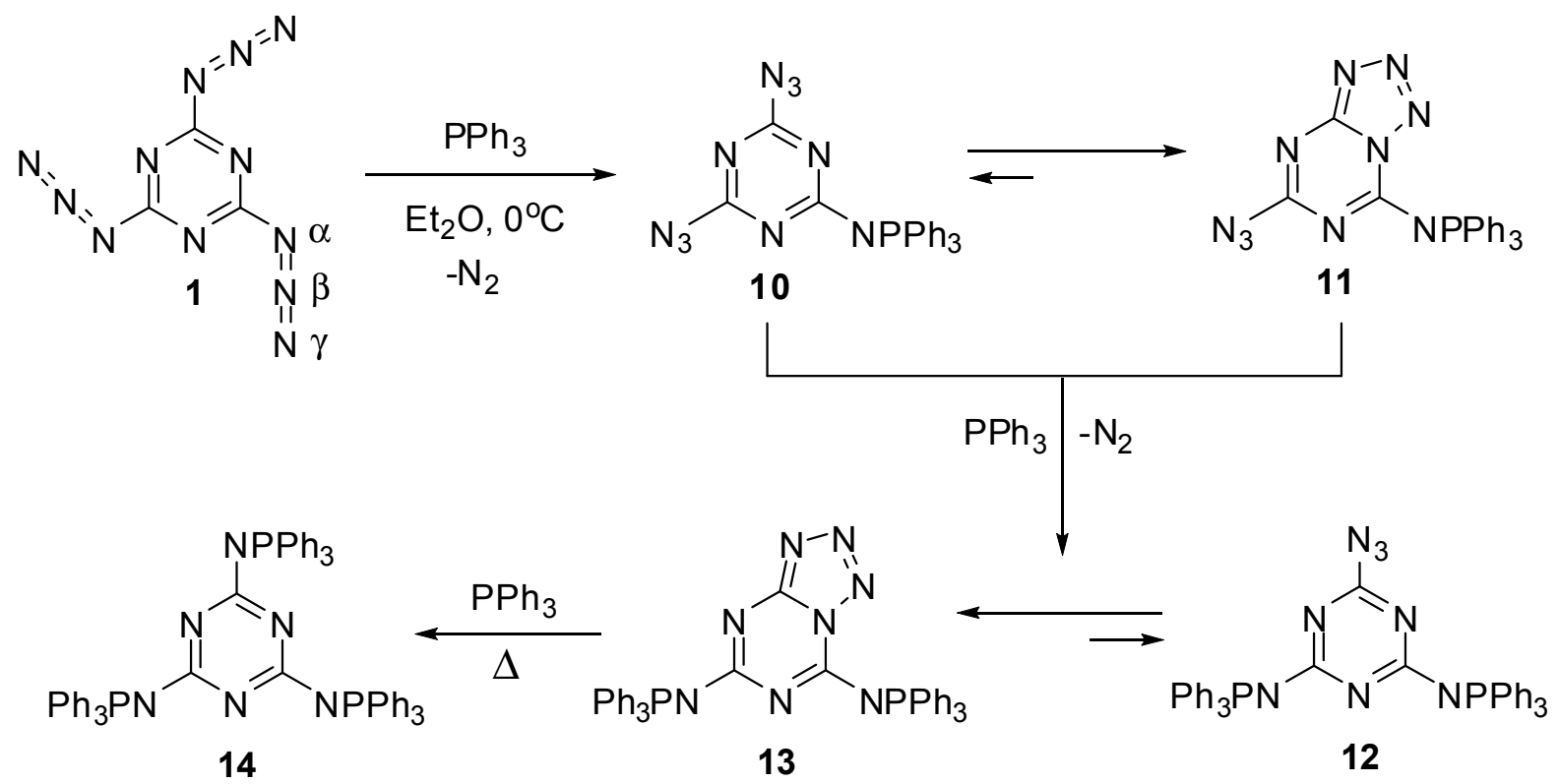

Scheme 4. Reactions of triazide 1 with triphenylphosphine.

In contrast to azides $\mathbf{1 0}$ and $\mathbf{1 2}$ containing strong electron-donating aza-ylide substituents on the triazine ring, triazide 1 itself does not isomerize to tetrazolo[5,1- $a]$-[1,3,5]triazines in organic solutions due to insufficiently high nucleophilicity of the endo-cyclic nitrogen atoms [64]. This triazide has become the first organic azide characterized with X-ray diffraction analysis [1-5]. These structural studies proved that organic azides have a linear structure of the azido groups. The molecule of $\mathbf{1}$ is planar with bent azido groups giving rise to $C_{3 \mathrm{~h}}$ symmetry (Scheme 4 ). The azido groups show $\pi$ bond localization with a short $\mathrm{N} \beta-\mathrm{N} \gamma$ bond distance of $1.1156 \AA$ (bond order $\approx 2.5$ ) and a longer $\mathrm{N} \alpha-\mathrm{N} \beta$ bond distance of $1.2658 \AA$ (bond order $\approx 1.5$ ) [63]. The $\mathrm{C}-\mathrm{N} \alpha-\mathrm{N} \beta$ angle is $112.5^{\circ}$, and the $\mathrm{N} \alpha-\mathrm{N} \beta-\mathrm{N} \gamma$ angle is slightly bent at $172.0^{\circ}$. The distance between the layers is $2.947 \AA$, and the crystal density is $1.736 \mathrm{~g} / \mathrm{cm}^{3}$ [63]. In IR spectra, the azido groups of 1 show four strong bands at $v 2192,2158,2115$ and $1198 \mathrm{~cm}^{-1}$ [63]. The ${ }^{13} \mathrm{C}-\mathrm{NMR}$ spectrum of 1 in acetone- $d_{6}$ displays a signal of the carbon atoms at $\delta 171.9 \mathrm{ppm}$ [63]. The ${ }^{15} \mathrm{~N}-\mathrm{NMR}$ spectrum of 1 in $\mathrm{CDCl}_{3}$ shows four signals of the nitrogen atoms at $\delta-131.3(\mathrm{~N} \gamma),-142.6(\mathrm{~N} \beta),-160.2$ (N-ring) and $-257.3(\mathrm{~N} \alpha)$ ppm [73].

In material chemistry, triazide $\mathbf{1}$ is often used as a reference compound in studies of new high-energy nitrogen-rich organic compounds [74-80]. Its sensitivity to impact, friction and spark is estimated as 
$6.2 \mathrm{~cm}\left(\mathrm{H}_{50}\right),<0.5 \mathrm{~kg}$ and $<0.36 \mathrm{~J}$, respectively [77]. This triazide has also one of the highest positive heats of formation $\left(\Delta H_{\mathrm{f}}=1053 \mathrm{~kJ} / \mathrm{mol}\right)$ among aromatic polyazides [78]. The thermal decomposition and detonation of 1 are used nowadays for preparation of $\mathrm{C}_{3} \mathrm{~N}_{4}$ and $\mathrm{C}_{3} \mathrm{~N}_{5}$ carbon nitrides and carbon nanotubes [6-9]. These materials possess unique mechanical, physical and chemical properties and are of considerable interest for industrial applications.

The first attempt to investigate the photochemistry of triazide $\mathbf{1}$ was undertaken by Moriarty and co-workers in 1966 [81]. It was found that low-temperature photolysis of crystalline 1 produces the stable at room temperature triplet nitrene $\mathbf{1 5}$ showing the largest zero-field splitting (zfs) parameter of $|D|=$ $1.445 \mathrm{~cm}^{-1}$ among all triplet arylnitrenes (Scheme 5). More recent studies of the photolysis of crystalline 1 at $4 \mathrm{~K}$ allowed the EPR detection of quintet dinitrene 16 with magnetic parameters $|D|=0.28 \mathrm{~cm}^{-1}$ and $|E|=0.058 \mathrm{~cm}^{-1}$, rather unusual for quintet dinitrenes [82]. A few years later, Sato and colleagues succeeded in EPR detection of septet trinitrene $\mathbf{1 7}$ formed during the photolysis of triazide $\mathbf{1}$ in solid nitrogen matrices $[14,15]$. It was found that three endo-cyclic nitrogen atoms of the triazine ring favor the extremely high localization of spins on the nitrene units of trinitrene 17. As a result, this trinitrene showed the largest negative value of $D=-0.123 \mathrm{~cm}^{-1}$ among all organic septet hexaradicals. Trinitrene 17 was photochemically unstable and decomposed to form triplet cyanonitrenes 18, that underwent further photochemical rearrangements to form triplet isocyanonitrene 19, dicyanocarbodiimide 20 and triplet dicyanocarbene 21. Overall, the photochemical studies showed that trinitrene $\mathbf{1 7}$ generated by the photolysis of triazide $\mathbf{1}$ possesses the record value of magnetic anisotropy among all organic hexaradicals, but is extremely reactive and photochemically unstable. Its decomposition leads to carbodiimide 20, similarly to the formation of $\mathrm{C}_{3} \mathrm{~N}_{4}$ carbon nitrides during the thermal and detonative decomposition of triazide 1.<smiles>Nc1nc(N)nc(N)n1</smiles>

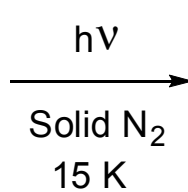<smiles>Nc1nc(N)nc(N)n1</smiles><smiles>Nc1nc(N)nc(N)n1</smiles><smiles>CNc1nc(N)nc(NC)n1</smiles>

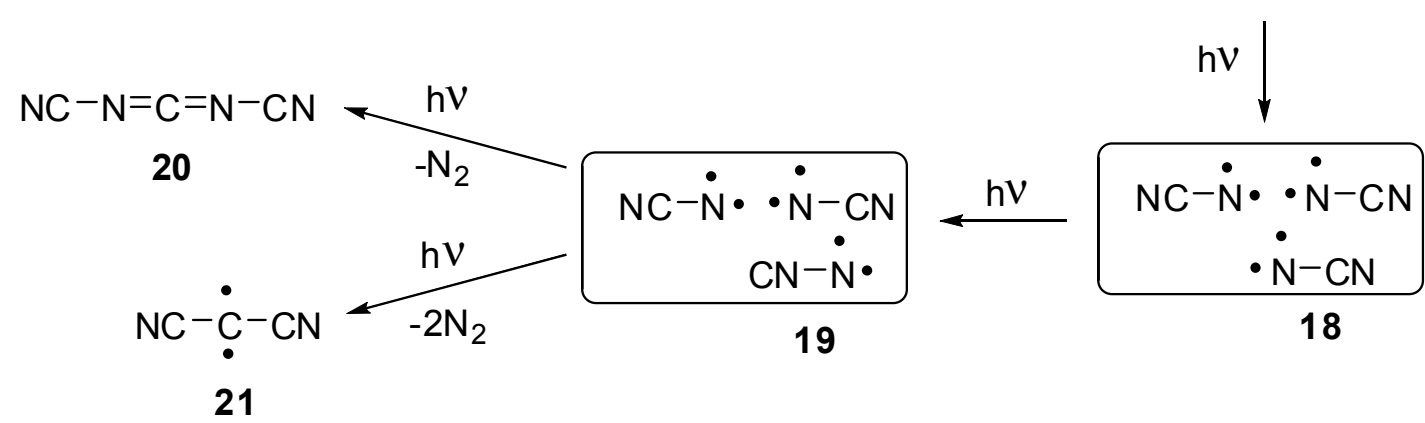

Scheme 5. Photolysis of triazide 1.

\section{Triazidopyrimidines}

At the moment, there are known just five triazidopyrimidines. The first of them, 2,4,6-triazidopyrimidine (22), was prepared by Pochinok and co-workers in 1979 (Scheme 6) [68]. The azidation of commercially 
available trichloride $\mathbf{2 3}$ with excess sodium azide in dimethylsulfoxide at room temperature gave triazide $\mathbf{2 2}$ in $96 \%$ yield. On the other hand, the diazotization of tris-hydrazine 24 with $\mathrm{NaNO}_{2}$ in acidic media afforded triazide $\mathbf{2 2}$ in $90 \%$ yield. This triazide was used as a starting material to prepare tris-triazenes 25a-c (Scheme 6) [68]. Recently, triazide 22 was obtained by azidation of trichloride 23 with excess sodium azide in acetone at room temperature in 91\% yield [78].

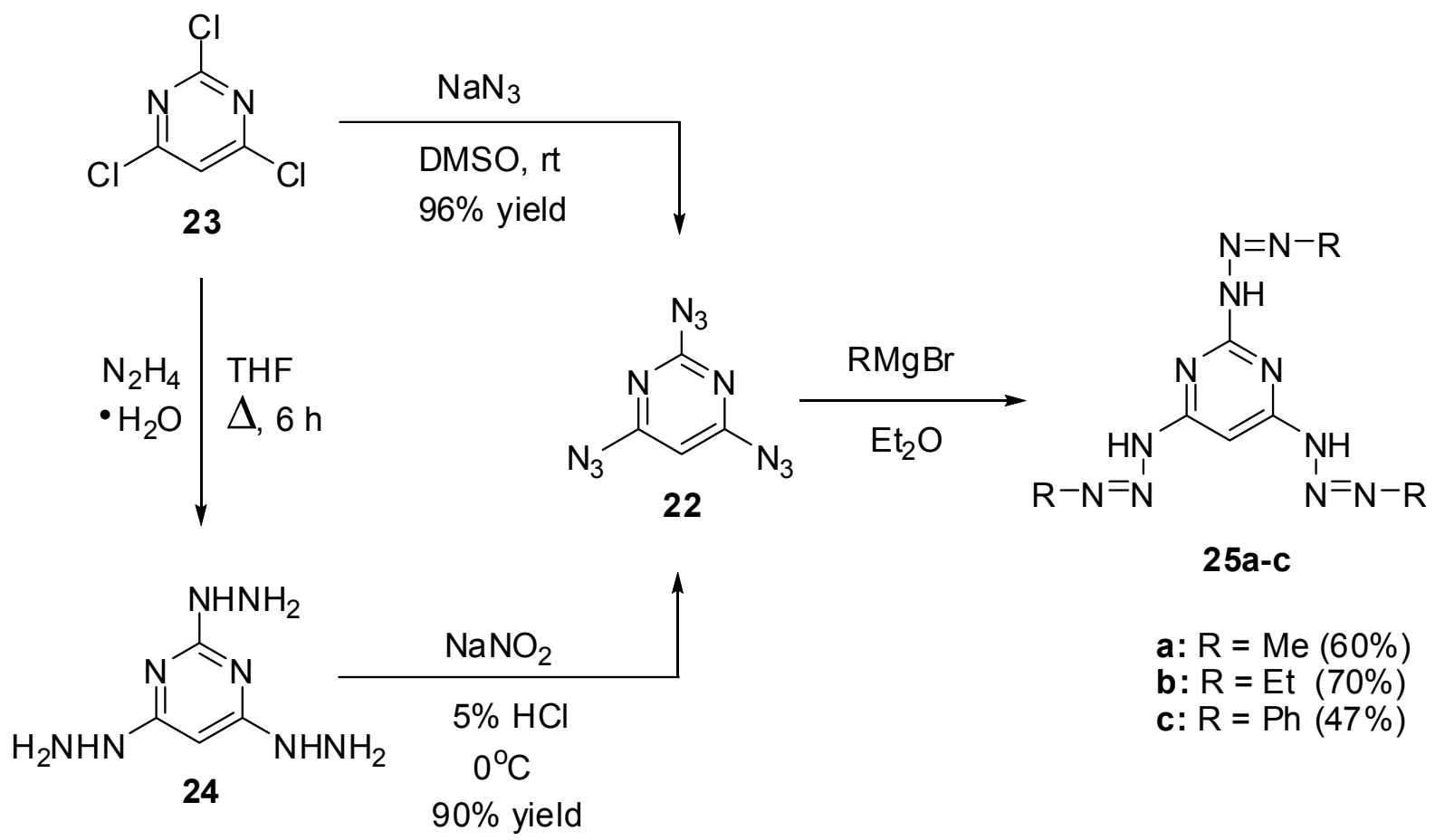

Scheme 6. Synthesis and reactions of triazide 22 with Grignard reagents.

On crystallization from ethanol, triazide $\mathbf{2 2}$ forms dense colorless crystals with a melting point of $98{ }^{\circ} \mathrm{C}[68,78]$. In comparison with cyanuric triazide, triazide 22 is much less sensitive to impact and friction. It may explode only under a very strong blow. Nevertheless, on working with $\mathbf{2 2}$, it is better to handle it only with plastic spatulas and use thick gloves behind a blast shield. In IR spectra, the azido groups of 22 show two weak bands at $v 2177$ and $2100 \mathrm{~cm}^{-1}$ and two bands of medium intensity at $v 2144$ and $1161 \mathrm{~cm}^{-1}$ [78]. The ${ }^{1} \mathrm{H}-\mathrm{NMR}$ spectrum of 22 in $\mathrm{CDCl}_{3}$ shows a signal of the proton at $\delta 6.88 \mathrm{ppm}$ [73]. The ${ }^{13} \mathrm{C}-\mathrm{NMR}$ spectrum of 22 in $\mathrm{CDCl}_{3}$ displays three signals of the carbons at $\delta 94.3$ (C-5), 161.5 (C-2) and 164.9 (C-4, C-6) ppm [73]. The ${ }^{15} \mathrm{~N}-\mathrm{NMR}$ spectrum of 22 in $\mathrm{CDCl}_{3}$ shows seven signals of the nitrogen atoms at $\delta-134.5\left(\mathrm{~N} \gamma, 4,6-\mathrm{N}_{3}\right),-135.1\left(\mathrm{~N} \gamma, 2-\mathrm{N}_{3}\right),-140.0\left(\mathrm{~N} \beta, 2-\mathrm{N}_{3}\right),-141.0$ $\left(\mathrm{N} \beta, 4,6-\mathrm{N}_{3}\right),-145.6\left(N\right.$-ring), $-262.7\left(\mathrm{N \alpha}, 2-\mathrm{N}_{3}\right)$ and $-264.8\left(\mathrm{N \alpha}, 4,6-\mathrm{N}_{3}\right) \mathrm{ppm}$ [73]. The ${ }^{13} \mathrm{C}-$ and ${ }^{15} \mathrm{~N}-\mathrm{NMR}$ spectra can be very helpful in predicting the chemical reactivity of nonequivalent azido groups of 2,4,6-triazidopyrimidines. Thus, quantum-chemical studies showed that the azido groups in positions 4 and 6 of triazide 22 are the most electron-deficient [73]. In ${ }^{15} \mathrm{~N}-\mathrm{NMR}$ spectra, these groups display the most shielded signal of the $\mathrm{N} \alpha$ atoms and should selectively react with electron-rich dipolarophiles, phosphines, phosphites and reductants to give diazides 26-30 (Scheme 7) [73]. On the other hand, the reaction of 22 with electron-deficient dimethyl acetylenedicarboxylate (DMAD) should selectively occur on the electron-rich azido group in position 2 of the pyrimidine ring to give adduct $\mathbf{3 1}$. 
<smiles>Nc1cc(N2C3CCC2C3)nc(N)n1</smiles><smiles>COC(=O)c1nnn(-c2nc(N)cc([N+](=O)[O-])n2)c1C(C)=O</smiles>
31<smiles>Cc1cn(-c2cc(N)nc(N)n2)nn1</smiles><smiles>[R]C#CC</smiles>

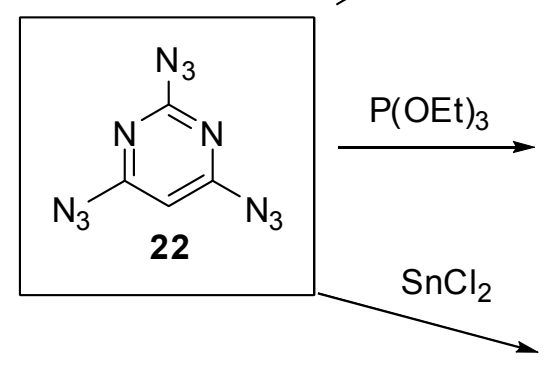<smiles>Nc1cc(N=Pc2ccccc2)nc(N)n1</smiles>

28<smiles>CCOP=Nc1cc(N)nc(N)n1</smiles><smiles>Nc1cc(N)nc(N)n1</smiles>

Scheme 7. Theoretically predicted reactions for triazide $\mathbf{2 2}$.

The high electron-deficiency of the azido groups in positions 4 and 6 of triazide 22 is also manifested in the most deshielded signals of the C-4 and C- 6 atoms in the ${ }^{13} \mathrm{C}-\mathrm{NMR}$ spectrum of this triazide. As a rule, the first stage of azidation of 2,4,6-trihalopyrimidines is the replacement of the halogen atom for the azido group in position 4 of the pyrimidine ring. Thus, trihalides 32a,b reacted with sodium azide in actetonitrile at room temperature to give only monoazides 33a,b and diazides 34a,b (Scheme 8) [83].<smiles>[X]c1c(F)nc(F)nc1F</smiles>

$32 a, b$

a: $X=F$

b: $\mathrm{X}=\mathrm{Cl}$<smiles>C[N+](C)=O</smiles>

Similarly to triazide 22, four other 2,4,6-triazidopyrimidines were synthesized (Scheme 9) [78]. The azidation of tetrachloride $35 \mathrm{a}$ with sodium azide in acetone at room temperature in the presence of tert-butylammonium bromide (TBAB) gave a mixture of triazide 36 and diazide 37 in 55\% and 21\% yields, respectively. The reactions of trichlorides $35 \mathbf{b}, \mathbf{c}$ with sodium azide in tetrahydrofuran (THF) at room temperature in the presence of TBAB gave triazide 38 and tetraazide 39 in $80 \%$ and $99 \%$ yields, respectively. Finally, the reaction of trichloride $\mathbf{3 5 d}$ with sodium azide in THF at room temperature in the presence of TBAB followed by addition of stannous chloride and trimethylsilylazide (TMSA) to intermediate products gave pentaazide $\mathbf{4 0}$ in 35\% yield. Despite the high-nitrogen content, tetraazide 39 
and pentaazide $\mathbf{4 0}$ are not very sensitive to impact and friction since their low melting points (22.5 and $-48^{\circ} \mathrm{C}$, respectively) [78].

The structure of triazide 38 was studied by X-ray diffraction analysis [78]. It was found that the least electron-deficient azido group in position 2 of $\mathbf{3 8}$ has a somewhat elongated $\mathrm{C}-\mathrm{N \alpha}$ bond distance $(1.412 \AA)$, a shortened $\mathrm{N} \alpha-\mathrm{N} \beta$ bond distance $(1.251 \AA)$ and the least bent $\mathrm{N} \beta-\mathrm{N} \beta-\mathrm{N} \gamma$ angle $\left(172.9^{\circ}\right)$. Similar parameters for the azido group in position 4 of 38 equal to $1.406 \AA, 1.257 \AA$ and $172.4^{\circ}$, respectively. At the same time, all three azido groups of $\mathbf{3 8}$ have the same $\mathrm{N} \beta-\mathrm{N} \gamma$ bond distances (1.119 $\AA$ ) and nearly the same $\mathrm{C}-\mathrm{N} \alpha-\mathrm{N} \beta$ angles $\left(\sim 113.5^{\circ}\right)$. The more bent $\mathrm{N} \alpha-\mathrm{N} \beta-\mathrm{N} \gamma$ angles and more elongated $\mathrm{N} \alpha-\mathrm{N} \beta$ bond distances in the azido groups in positions 4 and 6 of $\mathbf{3 8}$ suggest that these groups should be the least stable during thermolysis and decompose first to form triplet nitrenes and then amines.

Triazides 22, 38, 39 and 40 are typical high-energy nitrogen-rich compounds, which thermal and detonative decomposition is used for preparation of $\mathrm{C}_{3} \mathrm{~N}_{4}$ carbon nitrides and carbon nanotubes [78]. Triazide 22 is also of interest as an antitumor agent showing high activity against Sarcoma 180, Piss lymphosarcoma and Guerin carcinoma, along with low toxicity ( $>1000 \mathrm{mg} / \mathrm{kg})$ [84].

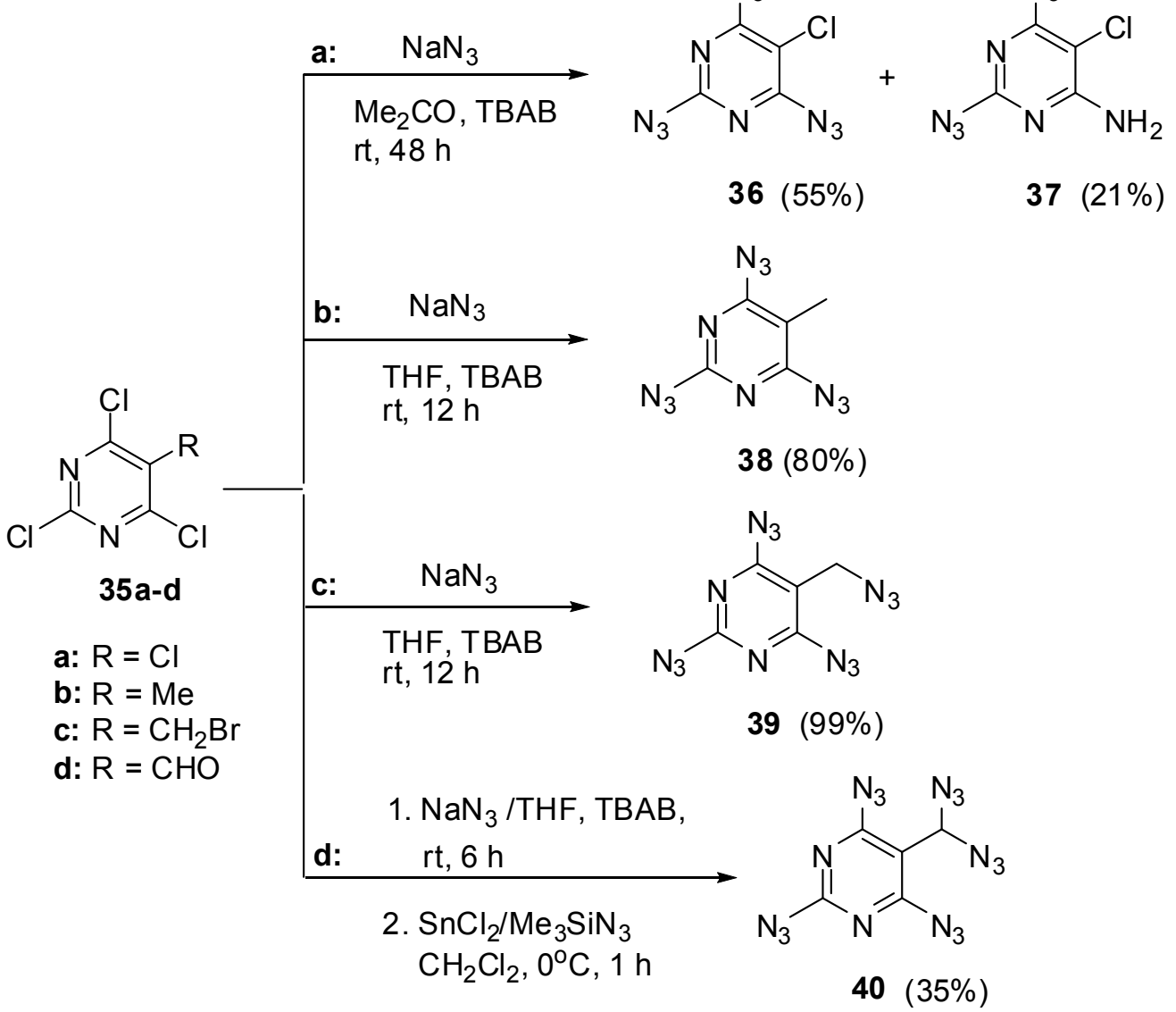

Scheme 9. Synthesis of triazides 36, 38, 39 and 41.

Triazides 22 and $\mathbf{3 6}$ were used as starting materials in several photochemical studies. First attempts to detect nitrenes during the photolysis of triazides $\mathbf{2 2}$ and $\mathbf{3 6}$ in frozen organic solutions at $77 \mathrm{~K}$ were unsuccessful [85]. Recently, the photolysis of $\mathbf{2 2}$ and $\mathbf{3 6}$ was studied in argon matrices at $5 \mathrm{~K}$ [30]. Using this technique, it was found that photochemical decompositions of $\mathbf{2 2}$ and $\mathbf{3 6}$ occur selectively to subsequently give triplet nitrenes 41a,b, quintet dinitrenes 42a,b and septet trinitrenes 43a,b (Scheme 10). 
Since the presence of only two endo-cyclic nitrogen atoms in the ring, trinitrene 43a showed $D=-0.1122 \mathrm{~cm}^{-1}$ that was by $\sim 10 \%$ smaller than the $D$-value of trinitrene 17. As in the case of trinitrene 17, trinitrenes $\mathbf{4 3 a}, \mathbf{b}$ were photochemically unstable and decomposed to form triplet nitrenes NCN and NNC as well as triplet carbenes NCCCN, HCCN and HCCCCN. Nitrenes NCN and NNC and carbene NCCCN were previously also observed during the photolysis of cyanuric triazide [15]. The formation of the same reactive intermediates during the photolysis of triazides 17 and 22 explained well the formation of the same $\mathrm{C}_{3} \mathrm{~N}_{4}$ carbon nitrides and carbon nanotubes during thermal and detonative decomposition of both triazides. At the same time, the photolysis of triazide 22 additionally produces carbenes HCCN and HCCCCN that are typical only for decomposition of azidopyrimidines. Of these two carbenes, the last one has never previously been generated in a laboratory, but was known as a component of interstellar matter [86].<smiles>[X]c1c(N)nc(N)nc1N</smiles>

22: $\mathrm{X}=\mathrm{H}$ 36: $\mathrm{X}=\mathrm{Cl}$<smiles>C#CC(=NC(=[W])NC)N(C)C</smiles>

47<smiles>[Y]C(C)C(C)N=[W]</smiles>

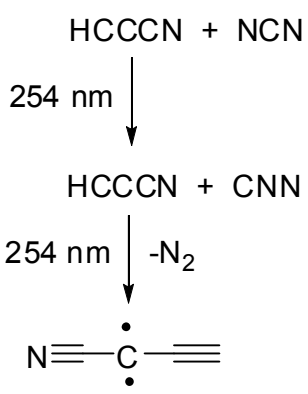

49<smiles>[X]c1c(N)nc(NC)nc1N</smiles>

41a: $X=H$

41b: $X=C l$<smiles>[X]c1c(N)nc(NC)nc1NC</smiles>

42a: $X=H$

42b: $X=\mathrm{Cl}$<smiles>[X]c1c(N(C)C)nc(N(C)C)nc1N(C)CC</smiles>

43a: $X=H$ 43b: $X=\mathrm{Cl}$

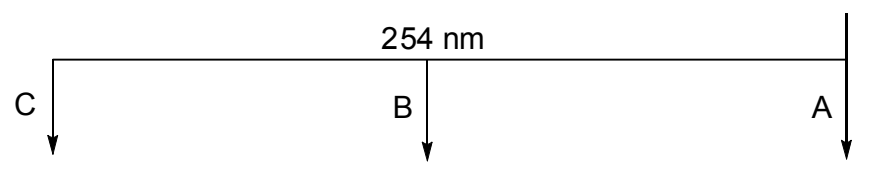<smiles></smiles>

46<smiles></smiles>

45

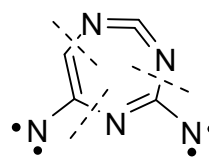

44

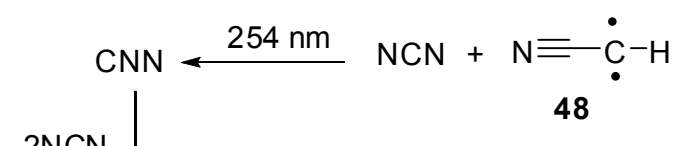

$254 \mathrm{~nm}$

$\mathrm{NC}-\mathrm{CN}$

21

Scheme 10. Photolysis of triazides 22 and $\mathbf{3 6 .}$

\section{Triazidopyridazines}

Due to azide-tetrazole isomerization, triazidopyrazines and triazidopyridazines may exist only as short-living intermediates formed during the azidation of the corresponding trihalides. Thus, recent studies have shown that azidation of tribromide $\mathbf{5 0}$ with sodium azide gave diazidotetrazole $\mathbf{5 2}$ in $45 \%$ yield (Scheme 11) [87]. It was postulated that this tetrazole is formed from intermediate triazide 51. The structure of 52 was confirmed by X-ray diffraction analysis. According to ${ }^{1} \mathrm{H}-\mathrm{NMR}$ studies, compound $\mathbf{5 2}$ exists 
in organic solutions exclusively as a tetrazole. On boiling in toluene, diazide $\mathbf{5 2}$ partially decomposed to form aminoazide $\mathbf{5 3}$ [87]. The latter also exists in organic solutions exclusively as a tetrazole.<smiles>Cc1c(N)nn2nnnc2c1N</smiles>

Scheme 11. Triazidation of tribromide $\mathbf{5 0 .}$

\section{Triazidopyridines}

2,4,6-Triazido-3,5-dibromopyridine (55a) was the first triazidopyridine, obtained by Moshchitskii and co-workers in 1979, using the reaction of pentabromopyridine (54a) with sodium azide (Scheme 12) [88]. The reaction was carried out in DMSO at room temperature for $15 \mathrm{~h}$ and gave triazide 55a (a brown solid with a melting point $85-86^{\circ} \mathrm{C}$ ) in $97 \%$ yield. The reactions of $\mathbf{5 5 a}$ with two and three molar equivalences of triethyl phosphite followed by acidic hydrolysis of the products with $5 \% \mathrm{HCl}$ gave bis-and tris-adducts that were assigned to compounds $\mathbf{5 6}$ and 57, respectively [88].

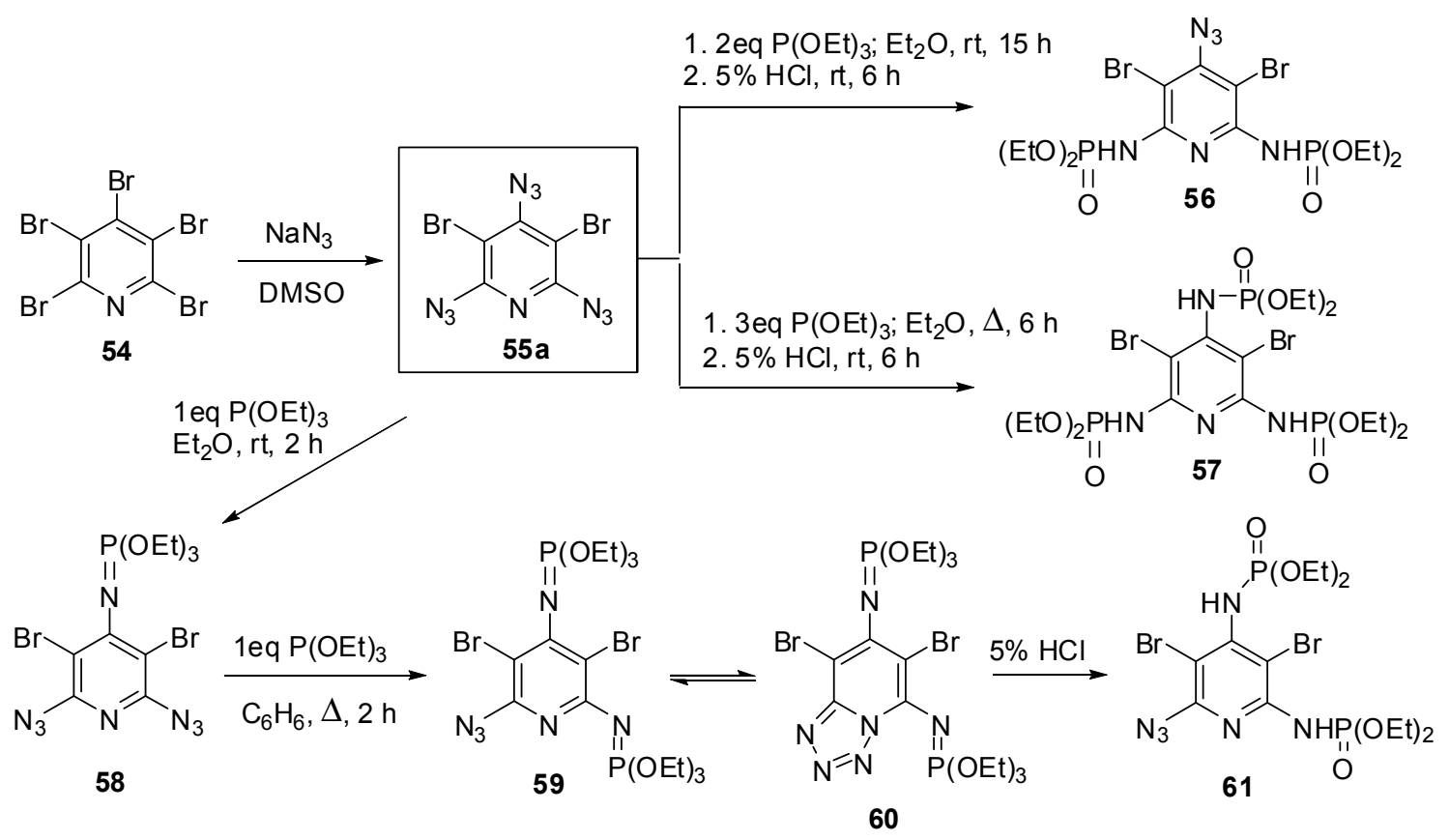

Scheme 12. Synthesis and Staudinger-phosphite reactions of triazide 55a.

Recently, triazide 55a has been prepared by the reaction of 54a with sodium azide in DMSO at $80{ }^{\circ} \mathrm{C}$ just for $30 \mathrm{~min}$ in $97 \%$ yield [89]. The addition of an equimolar amount of triethyl phosphite to 55a resulted in the formation of diazide $\mathbf{5 8}$ as a single product (Scheme 12) [89]. The latter reacted with an equimolar amount of triethyl phosphite on boiling in benzene to form a mixture of compounds $\mathbf{5 9}$ and 60 in a nearly equal ratio. The hydrolysis of the mixture of 59 and 60 with $5 \% \mathrm{HCl}$ afforded azide 61 as a single product [89]. The structures of compounds 58-60 were unambiguously confirmed by the data 
of ${ }^{1} \mathrm{H}-{ }^{13} \mathrm{C}$ - and ${ }^{31} \mathrm{P}-\mathrm{NMR}$ spectroscopic studies. According to these studies, the $\gamma$-azido group of triazide 55a is the most electron-deficient and, as the result, the most reactive in the Staudinger reactions. After triazide 55a, nine 2,4,6-triazidopyridines 55b-j have been synthesized (Scheme 13) [90-100].<smiles>[X]c1nc([X])c([R])c([X])c1[R]</smiles><smiles>CC(=O)OCCNN</smiles>

54b: $X=R^{1}=R^{2}=C l$

54c: $X=C l, R^{1}=R^{2}=C N$

54d: $X=\mathrm{R}^{1}=\mathrm{Cl}, \mathrm{R}^{2}=\mathrm{CN}$

54e: $X=\mathrm{R}^{1}=\mathrm{Cl}, \mathrm{R}^{2}=\mathrm{CF}_{3}$

54f: $X=R^{1}=F, R^{2}=C N$<smiles>[R]c1c(F)nc(F)c([R])c1F</smiles><smiles>[R]c1c(N)nc(N)c([R])c1N</smiles>

55b: $R^{1}=R^{2}=C l$

[Ref. 90]

55c: $R^{1}=R^{2}=C N$

[Refs. 91,92]

55d: $\mathrm{R}^{1}=\mathrm{Cl}, \mathrm{R}^{2}=\mathrm{CN}$ [Refs. 93,94]

55e: $\mathrm{R}^{1}=\mathrm{Cl}, \mathrm{R}^{2}=\mathrm{CF}_{3}$ [Ref. 95]

55f: $R^{1}=F, R^{2}=C N \quad$ [Ref. 95]<smiles>[R]c1c(N)nc(N)c([R])c1N</smiles>

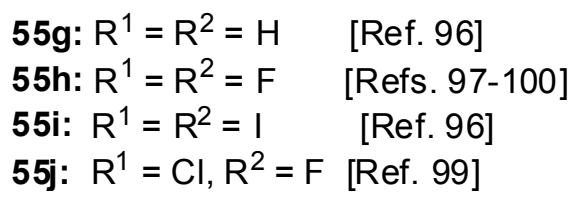

Scheme 13. Synthesis of triazides $\mathbf{5 5 b}-\mathbf{j}$.

Owing to the presence of strong electron-withdrawing cyano- and trifluoromethyl-substituents on the

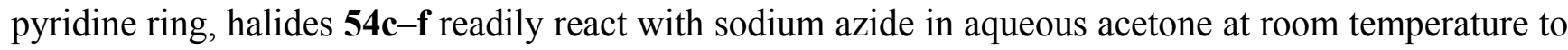
form triazides 55c-f in $86 \%-98 \%$ yields [91-95]. The least activated halide $\mathbf{5 4 b}$ formed triazide $\mathbf{5 5 b}$ (98\%) on interaction with sodium azide in aqueous acetone only at temperature above $30{ }^{\circ} \mathrm{C}$ [90]. Similar reactions of trifluoropyridines $\mathbf{5 4} \mathbf{g}-\mathbf{j}$ with sodium azide in boiling aqueous acetone stopped, as a rule, on the stage of formation of the corresponding 2,4-diazidopyridines [97,98]. At the same time, fluorides $\mathbf{5 4 g - j}$ readily underwent triazidation in hot DMSO to form triazides $\mathbf{5 5} \mathbf{g}-\mathbf{j}$ in $86 \%-96 \%$ yield [96,99]. In all cases, the first stage of the reaction was the replacement of the halogen atom in position 4 of the pyridine ring.

Triazides 55a-j are solid materials ( $\mathrm{mp} 63-135^{\circ} \mathrm{C}$ ) that are almost insensitive to impact, friction, and electrostatic discharge. Only triazides $\mathbf{5 5 c}$ and $\mathbf{5 5 g}$ may explode under a very strong blow $[92,101]$. In the IR spectra, the azido groups of 55a-j show two strong bands in the $v 2180-2120 \mathrm{~cm}^{-1}$ region and a weak band about $v 2100 \mathrm{~cm}^{-1}[90-100]$. In ${ }^{15} \mathrm{~N}-\mathrm{NMR}$ spectra, the most electron-deficient $\gamma$-azido groups of 55a-j display the most shielded $\mathrm{N} \alpha$ signals [73]. Thus, the ${ }^{15} \mathrm{~N}-\mathrm{NMR}$ spectrum of triazide 55a shows seven signals of the nitrogen atoms at $\delta-129.0(N$-ring $),-134.8\left(\mathrm{~N} \gamma, \alpha-\mathrm{N}_{3}\right),-139.8\left(\mathrm{~N} \beta, \alpha-\mathrm{N}_{3}\right)$, $-140.8\left(\mathrm{~N} \gamma, \gamma-\mathrm{N}_{3}\right),-144.8\left(\mathrm{~N} \beta, \gamma-\mathrm{N}_{3}\right),-265.8\left(\mathrm{N \alpha}, \alpha-\mathrm{N}_{3}\right)$ and $-276.2 \mathrm{ppm}\left(\mathrm{N \alpha}, \gamma-\mathrm{N}_{3}\right)$ [89]. The high electron-deficiency of the $\gamma$-azido groups of triazides $\mathbf{5 5 a}-\mathbf{j}$ is also manifested in the more shielded signals of the $\mathrm{C}-4$ atoms in the ${ }^{13} \mathrm{C}-\mathrm{NMR}$ spectrum of these triazides. Thus, the ${ }^{13} \mathrm{C}-\mathrm{NMR}$ spectrum of triazide 55a shows three signals of the carbon atoms at $\delta 98.2(\mathrm{C} \beta), 147.4(\mathrm{C} \gamma)$ and $151.0 \mathrm{ppm}(\mathrm{C} \alpha)[89]$. 
In crystals, the $\alpha$-azido groups of triazides 55b [102], 55c [103], 55d [95], 55e [104], 55f [105] and 55h [100] show typical for aryl azides values of the $\mathrm{C}-\mathrm{N \alpha}(\sim 1.40 \AA), \mathrm{N} \alpha-\mathrm{N} \beta(\sim 1.26 \AA)$ and $\mathrm{N} \beta-\mathrm{N} \gamma$ $(\sim 1.12 \AA)$ bond distances and the $\mathrm{C}-\mathrm{N} \alpha-\mathrm{N} \beta\left(\sim 113^{\circ}\right)$ and $\mathrm{N} \alpha-\mathrm{N} \beta-\mathrm{N} \gamma\left(\sim 172^{\circ}\right)$ angles. Almost the same values of the $\mathrm{C}-\mathrm{N} \alpha(\sim 1.39 \AA), \mathrm{N} \alpha-\mathrm{N} \beta(\sim 1.25 \AA)$ and $\mathrm{N} \beta-\mathrm{N} \gamma(\sim 1.12 \AA)$ bond distances are observed as well in the $\gamma$-azido groups of triazides $\mathbf{5 5 b}-\mathbf{f}$ and $\mathbf{5 5 h}$. However, these groups have essentially larger the $\mathrm{C}-\mathrm{N} \alpha-\mathrm{N} \beta\left(\sim 120^{\circ}\right)$ angles and smaller the $\mathrm{N} \alpha-\mathrm{N} \beta-\mathrm{N} \gamma\left(\sim 169^{\circ}\right)$ angles. In addition, the $\mathrm{C}-\mathrm{C}-\mathrm{N} \alpha-\mathrm{N} \beta$ torsion angles of these groups vary from $2(\mathbf{5 5 h})$ till $40^{\circ}(\mathbf{5 5 e})$, depending on the bulkiness of the substituents in positions 3 and 5 of the pyridine ring. According to theory, the smaller the $\mathrm{N} \alpha-\mathrm{N} \beta-\mathrm{N} \gamma$ angle and the larger the $\mathrm{C}-\mathrm{N} \alpha-\mathrm{N} \beta$ angle in azides, the higher the reactivity of azides in reactions with dipolarophiles, phosphines, phospites and reductans [105-107].

Owing to the presence of nonequivalent azido groups on the pyridine ring, triazides 55a-d were used as model compounds to investigate selective reactions on the azido groups of aromatic polyazides [34,35]. It was found that the Staudinger phosphorylation of triazides $\mathbf{5 5 b}-\mathbf{d}$ in ether at $0{ }^{\circ} \mathrm{C}$ occurs selectively on the most electron-deficient $\gamma$-azido groups to give iminophosphoranes $\mathbf{6 2 b}-\mathbf{d}$ in $93 \%-97 \%$ yields (Scheme 14) [93,108]. Similarly to preparation of tris-adduct 57 from triazide 55a (Scheme 12), diazide 62c reacted with an excess of triphenylphosphine on boiling in benzene to give tris-adduct $\mathbf{6 3}$ in $80 \%$ yield [93].<smiles>[X]c1c(N)nc(N)c([X])c1N</smiles>

$55 b-d$

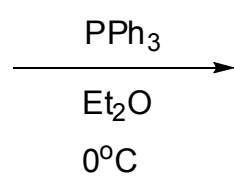

b: $\mathrm{X}=\mathrm{Y}=\mathrm{Cl}$

c: $X=Y=C N$

$\mathrm{d}: \mathrm{X}=\mathrm{Cl}, \mathrm{Y}=\mathrm{CN}$

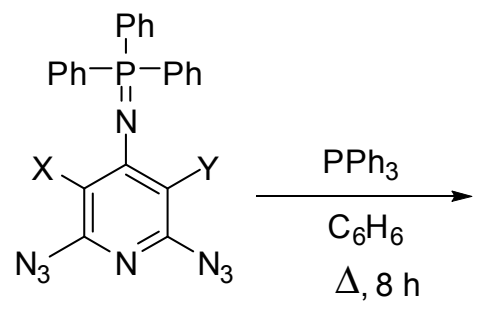

$62 \mathrm{~b}-\mathrm{d}$

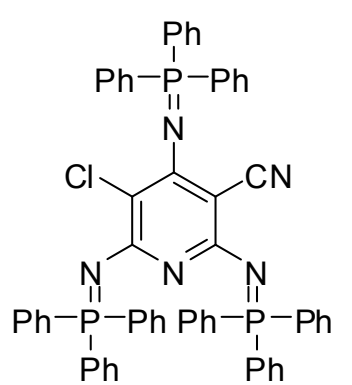

$63(80 \%)$

Scheme 14. Selective Staudinger reactions of triazides $\mathbf{5 5 b} \mathbf{d}$.

Beside selective phosphorylation, the $\gamma$-azido groups of triazides $\mathbf{5 5 b} \mathbf{b} \mathbf{d}$ are selectively reduced to amines. Thus, the reactions of triazides $\mathbf{5 5 b}, \mathbf{c}$ with stannous chloride in methanol at room temperature afforded aminodiazides 64b,c (Scheme 15) [109]. The more electron-deficient diazide 64c was further reduced with stannous chloride in methanol at room temperature till diamine $\mathbf{6 5}$.

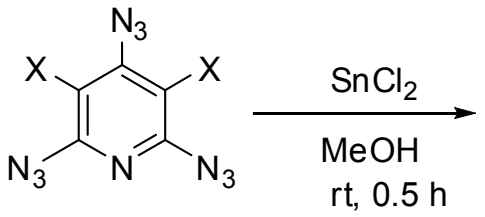

$55 b, c$

b: $\mathrm{X}=\mathrm{Cl}$

c: $\mathrm{X}=\mathrm{CN}$

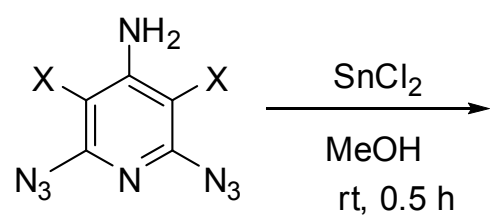

$64 \mathrm{~b}(88 \%)$

$64 \mathrm{c}(78 \%)$<smiles>N#Cc1c(N)nc(N)c(C#N)c1N</smiles>

$65(85 \%)$

Scheme 15. Selective reduction of triazides $\mathbf{5 5 b}, \mathbf{c}$. 
The electron-deficient $\gamma$-azido groups of triazides $\mathbf{5 5} \mathbf{b}$ - $\mathbf{d}$ are also the most reactive toward electron-rich dipolarophiles [90,110]. Thus, the reaction of triazide $\mathbf{5 5 c}$ with norbornene in ether at $0{ }^{\circ} \mathrm{C}$ occurred regio- and stereoselectively to give exo-adduct 66c in high yield (Scheme 16) [110]. At room temperature, triazide 66c readily reacted with an excess of norbornene to form tris-adduct $67 \mathbf{c}$ in almost quantitative yield. Similar reactions of less electron-deficient triazides $\mathbf{5 5 b}, \mathbf{d}$ stopped at the stage of formation of

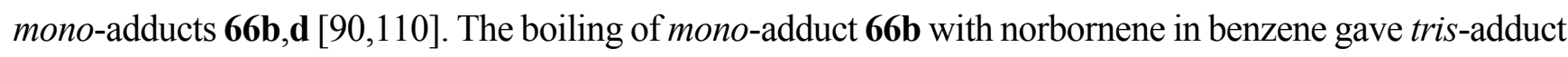
$\mathbf{6 7 b}$ in $56 \%$ yield [110]. On the other hand, the reactions of mono-adduct $\mathbf{6 6} \mathbf{b}$ with norbornene in ether at room temperature in the presence of $\mathrm{Rh}_{2}(\mathrm{OAc})_{4}$ as a catalyst gave tris-adduct $67 \mathbf{b}$ in $90 \%$ yield [110].

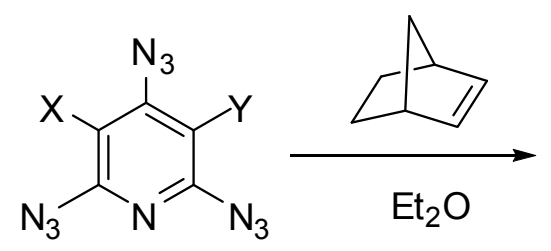

$55 b-d$

b: $X=Y=C l$

c: $X=Y=C N$

d: $X=\mathrm{Cl}, \mathrm{Y}=\mathrm{CN}$

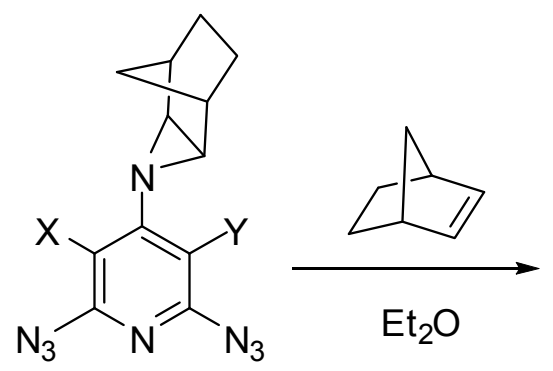

$66 b-d$

Scheme 16. Selective addition of norbornene to triazides $\mathbf{5 5 b}-\mathbf{d}$.

The reactions of triazides $\mathbf{5 5 c}, \mathbf{d}$ with electron-rich tert-butylacetylene in ether at room temperature also occurred regioselectively on the $\gamma$-azido groups to form mono-adducts $\mathbf{6 8 c}$,d in $\sim 85 \%$ yield (Scheme 17) [111]. Similar reactions of triazides $\mathbf{5 5 c , d}$ with less sterically hindered $n$-butylacetylene gave mixtures of diazides $\mathbf{6 9 c}, \mathbf{d}(\sim 82 \%)$ and 70c,d ( $\sim 8 \%$ yield) [111].<smiles>[X]c1c(N)nc(N)c(C#N)c1-n1cc(C(C)(C)C)nn1</smiles>

$68 \mathrm{c}, \mathrm{d}$

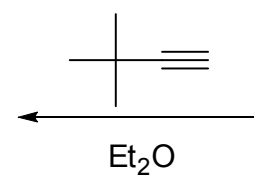

$\mathrm{rt}, 1 \mathrm{~h}$

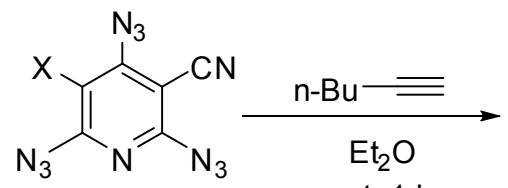

55c,d

c: $\mathrm{X}=\mathrm{CN}$

d: $\mathrm{X}=\mathrm{Cl}$<smiles>[X]c1c(N)nc(N)c([Y])c1-n1cc(C([R18])C)nn1</smiles>

$69 \mathrm{c}, \mathrm{d}$<smiles>[Y]c1c(N)nc(N)c([X])c1-n1nncc1[R16]#N</smiles>

70c,d

Scheme 17. Selective addition of butylacetylenes to triazides $\mathbf{5 5 c}, \mathbf{d}$.

In ether at $0{ }^{\circ} \mathrm{C}$, the extremely reactive tert-butylphosphaacetylene reacted with triazides $\mathbf{5 5 c}, \mathbf{d}$ to form mono-adducts 71c,d (Scheme 18) [91,112,113]. The latter reacted with an excess tert-butylphosphaacetylene in ether at room temperature to give tris-adducts $\mathbf{7 2 c}, \mathbf{d}[91,112,113]$. 


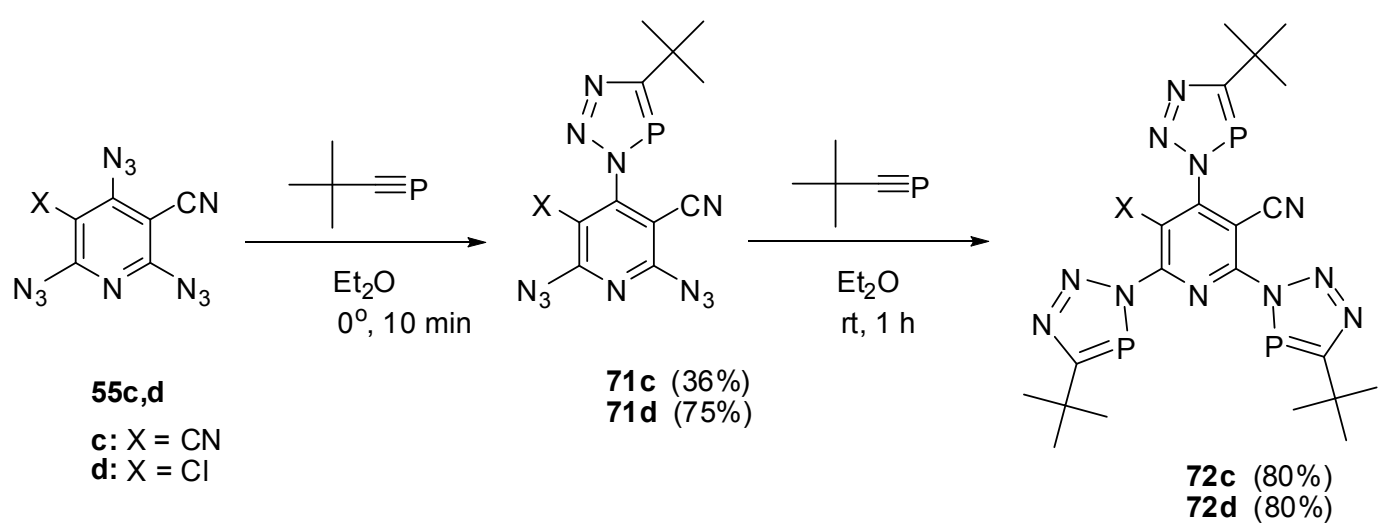

Scheme 18. Selective addition of tert-butylphosphaacetylene to triazides $\mathbf{5 5 c}, \mathbf{d}$.

Since high electron-deficiency, triazides $\mathbf{5 5 a}-\mathbf{j}$ are not much reactive toward electron-deficient dipolarophiles. The reaction of triazide $\mathbf{5 5} \mathbf{c}$ with DMAD in ether at room temperature for 2 weeks occurred selectively on the least electron-deficient $\alpha$-azido group to give triazole 73 in 34\% yield (Scheme 19) [114]. Similar reaction of less electron-deficient triazide $\mathbf{5 5 \mathbf { b }}$ with DMAD led to the formation of bis-adduct 74 in $75 \%$ yield [114].<smiles>CCOC(C)(C)O[Na]</smiles>

$73(34 \%)$<smiles>[X]c1c(N)nc(N)c([X])c1N</smiles>

c: $X=C N$<smiles>COC(=O)c1nnn(-c2nc(-n3nnc(C(OC)OC)c3C(=O)OC)c(Cl)c(N)c2Cl)c1C(=O)OC</smiles>

Scheme 19. Reactions of triazides $\mathbf{5 5 b}, \mathbf{c}$ with dimethyl acetylenedicarboxylate.

Owing to high electron-deficiency, triazides $\mathbf{5 5 a}-\mathbf{j}$ readily react with aliphatic amines. Thus, a brief (5 min) boiling of triazide 55d in pyrrolidine or piperidine gave diamines $\mathbf{7 5}$ and $\mathbf{7 6}$ in high yields (Scheme 20) [115]. Most probably, these reactions occur by a radical mechanism involving electron transfer from amines to triazides followed by the collapse of diradical amine-azide pairs into aminopyridine and gaseous $\mathrm{HN}_{3}$. The reactions stop at the stage of bis-amination since low electron-deficiency of azides $\mathbf{7 5}$ and 76 [115]. Formally, these reactions are identical to amination of cyanuric triazide with aliphatic amines (see Scheme 2).<smiles>N#Cc1c(N2CCCC2)nc(N)c(Cl)c1N1CCCC1</smiles>

$75(88 \%)$

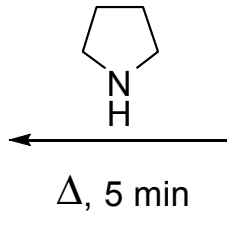<smiles>N#Cc1c(N)nc(N)c(Cl)c1N</smiles>

$55 d$

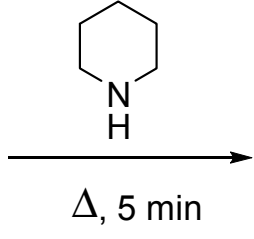<smiles>N#Cc1c(N2CCCCC2)nc(N)c(Cl)c1N1CCCCC1</smiles>

$76(92 \%)$

Scheme 20. Reactions of triazide 55d with aliphatic amines. 
On thermolysis, triazides 55a-j undergo selective cleavage of the least durable $\mathrm{N}-\mathrm{N}_{2}$ bonds of the $\gamma$-azido groups. Thus, the reflux of triazide 55b in $p$-dichlorobenzene at $160{ }^{\circ} \mathrm{C}$ for $12 \mathrm{~h}$ gave aminodiazide 77 in 56\% yield (Scheme 21) [116]. On the other hand, the photolysis of triazide $55 \mathrm{~b}$ in frozen at $77 \mathrm{~K}$ organic solutions occurred selectively on the $\alpha$-azido groups to give triplet nitrene $\mathbf{7 8 b}$ and quintet dinitrene $\mathbf{7 9 b}$ as the major paramagnetic products (Scheme 21) [12,117]. This selectivity was explained by extremely low stability of the excited states of $\mathbf{5 5 b}$ arising after local excitation of the $\alpha$-azido groups [117].

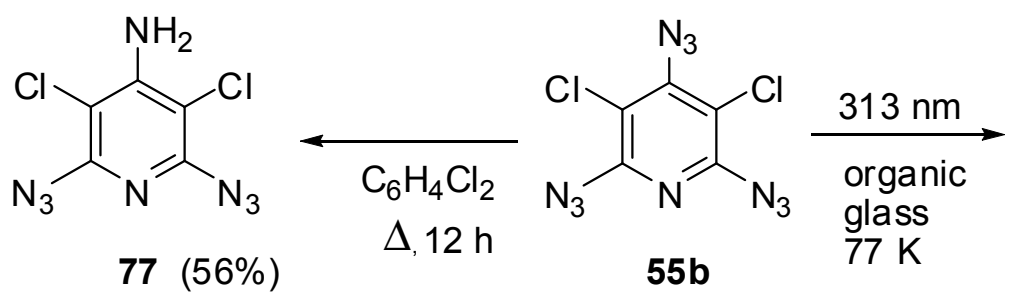<smiles>CNc1c(N)nc(N)c(Cl)c1N</smiles>

Scheme 21. Selective thermolysis and photolysis of triazide $\mathbf{5 5 b}$.

Triazides 55a-j have played an important role in investigations of high-spin organic compounds. Before that, nothing was known about the UV-vis and IR spectra of organic hexaradicals with the ground septet spin-state. Even EPR spectra of septet trinitrenes were never reported. It was surmised that such trinitrenes should show the magnetic anisotropy of $D \approx-0.055 \mathrm{~cm}^{-1}[10,118]$. The photolysis of triazides $\mathbf{5 5 b}$ and $55 \mathbf{h}$ in cryogenic matrices allowed the first registration of IR and UV-vis spectra of septet trinitrenes 80b and 80d (Scheme 22) [11,13]. It was found that these trinitrenes are photochemically very stable and do not rearrange into low-molecular-weight products. Moreover, high-spin nitrenes generated by the photolysis or $\gamma$-radiolysis of triazide 55b were stable in crystals of the host triazide even at $230 \mathrm{~K}$ [102,103]. EPR studies of the photolysis of triazides 55a-j showed that containing light atoms trinitrenes $\mathbf{5 5} \mathbf{b}-\mathbf{h}$ have nearly the same magnetic parameters of $D \approx-0.102 \mathrm{~cm}^{-1}$ and $E \approx 0.003 \mathrm{~cm}^{-1}$, independent on substituents in positions 3 and 5 of the pyridine ring [20-23,119]. Only trinitrene 80a was an exception. Due to the presence of two heavy bromine atoms on the pyridine ring, this trinitrene showed the record value of $|D|=0.297 \mathrm{~cm}^{-1}$ among all organic septet hexaradicals [26]. Recent high-level ab initio calculations have proved that trinitrene $80 \mathrm{a}$ has the negative sign of $D$ and can be assigned to strong organic magnetic molecules [120]. The finding that heavy atoms drastically strengthen the magnetic properties of organic polyradicals opened up principally new prospects in design of organic magnetic materials.<smiles>[R]c1c(N)nc(N)c([R])c1N</smiles>

55a-j<smiles>[R]c1c(NC)nc(NC)c([R])c1[N]C</smiles>

$80 a-j$

a: $\mathrm{R}^{1}=\mathrm{R}^{2}=\mathrm{Br} ; \mathbf{b}: \mathrm{R}^{1}=\mathrm{R}^{2}=\mathrm{Cl} ; \mathbf{c}: \mathrm{R}^{1}=\mathrm{R}^{2}=\mathrm{CN}$;

d: $\mathrm{R}^{1}=\mathrm{Cl}, \mathrm{R}^{2}=\mathrm{CN} ; \mathbf{e}: \mathrm{R}^{1}=\mathrm{Cl}, \mathrm{R}^{2}=\mathrm{CF}_{3} ; \mathbf{f}: \mathrm{R}^{1}=\mathrm{F}, \mathrm{R}^{2}=\mathrm{CN}$;

g: $\mathrm{R}^{1}=\mathrm{R}^{2}=\mathrm{H} ; \mathbf{h}: \mathrm{R}^{1}=\mathrm{R}^{2}=\mathrm{F} ; \mathbf{i}: \mathrm{R}^{1}=\mathrm{R}^{2}=\mathrm{l} ; \mathbf{j}: \mathrm{R}^{1}=\mathrm{Cl}, \mathrm{R}^{2}=\mathrm{F}$

Scheme 22. Photochemical generation of septet trinitrenes from triazides $\mathbf{5 5 a}-\mathbf{j}$. 


\section{Triazidobenzenes}

To the moment, there are known just nine triazidobenzenes. The first of them, 1,3,5-triazido-2,4,6trinitrobenzene (81), was prepared by Turek in 1931, using the azidation of trichloride $\mathbf{8 2}$ with sodium azide in hot methanol (Scheme 23) [121]. Later, a more efficient way to preparation of $\mathbf{8 1}$, based on nitration of triazide $\mathbf{8 3}$, was developed [122-124]. The intermediate triazide $\mathbf{8 3}$ is readily obtained by refluxing trichloride $\mathbf{8 4}$ with sodium azide in the mixture of acetone and methanol [122]. Triazides $\mathbf{8 1}$ and 83 can also be obtained in $65 \%-90 \%$ yields by azidation of the corresponding chlorides 82 and 84 with sodium azide in aqueous acetone, methanol or dimethylsulfoxide solutions [125,126]. On boiling in acetic acid, both triazides 81 and 83 form benzofuroxans 85 and 86 in almost quantitative yields (Scheme 23) [122,126].<smiles>O=[N+]([O-])c1c(Cl)c(Cl)c([N+](=O)[O-])c([N+](=O)[O-])c1Cl</smiles>

82<smiles>O=[N+]([O-])c1c(Cl)cc(Cl)c([N+](=O)[O-])c1Cl</smiles>

84

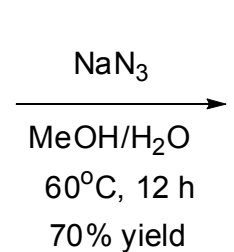

$70 \%$ yield<smiles>Nc1c([N+](=O)[O-])c(N)c([N+](=O)[O-])c(N)c1[N+](=O)[O-]</smiles>

81

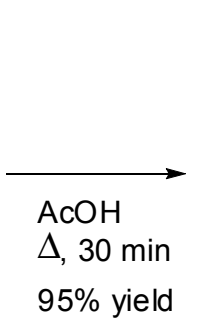

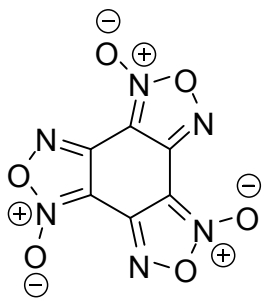

85

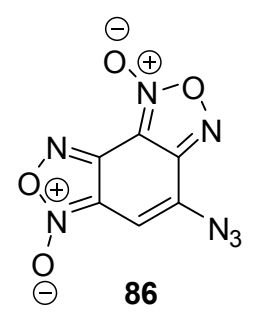

Scheme 23. Synthesis of triazides 81 and 83 .

Triazides $\mathbf{8 1}$ and $\mathbf{8 3}$ are bright yellow solids with melting points of $107-108$ and $128-130{ }^{\circ} \mathrm{C}$, respectively [121-126]. Both triazides are typical high energy density organic materials that are rather sensitive toward impact and friction and very sensitive toward electrostatic discharge [74,124].

The nucleophilic substitution reactions were also used to prepare triazidobenzenes $\mathbf{8 8 ,} 90$ and $\mathbf{9 2 a - c}$ from the corresponding halides (Scheme 24) [127-130]. The azidation of halides $\mathbf{8 7 a}, \mathbf{b}$ with sodium azide in boiling acetonitrile gave triazide $\mathbf{8 8}$ in high yield [127,128]. Similarly, the azidation of trichloride $\mathbf{8 9}$ with trimethylsilylazide in acetonitrile at room temperature afforded triazide $\mathbf{9 0}$ in quantitative yield [129]. Unfortunately, halides $\mathbf{8 7 a}, \mathbf{b}$ and $\mathbf{8 9}$ are hardly available compounds what seriously limits the use of triazides $\mathbf{8 8}$ and $\mathbf{9 0}$ in practice. Thus, tribromide $\mathbf{8 7 b}$ is prepared from mesitylene in six steps [128]. Both triazides 88 (m.p. $161{ }^{\circ} \mathrm{C}$ ) and $\mathbf{9 0}$ (m.p. $113-114{ }^{\circ} \mathrm{C}$ ) are solids that are almost insensitive toward impact, friction and electrostatic discharge. Triazide $\mathbf{8 8}$ has the highest melting point among all six-membered aromatic triazides [128]. Recently, a simple and efficient method of preparation of triazidobenzenes 92a-c from commercially available trifluorides $91 \mathbf{a}-\mathbf{c}$ has been developed (Scheme 24) [130]. Trifluorides 91a and 91c readily underwent chemoselective defluorination on heating in dimethylsulfoxide solutions with sodium azide to form triazides $92 \mathbf{a}$ and $92 \mathbf{c}$ in high yields. However, a similar reaction of trifluoride 91b, containing the least electron-withdrawing substituents on the benzene ring, stopped at the stage of 
formation of a mixture of diazide 93 and triazide $92 \mathrm{~b}$. The latter was obtained in $81 \%$ yield by refluxing the mixture of 93 and $\mathbf{9 2 b}$ with sodium azide in aqueous acetone, from which triazide $\mathbf{9 2 b}$ precipitated. All triazides 92a (m.p. $94{ }^{\circ} \mathrm{C}$ ), 92b (m.p. $105{ }^{\circ} \mathrm{C}$ ) and 92c (m.p. $83{ }^{\circ} \mathrm{C}$ ) are colorless solids that are insensitive toward impact, friction and electrostatic discharge. Owing to their simple and efficient preparation from commercially available starting materials, triazides $\mathbf{9 2 a - c}$ may be of considerable interest as cross-linking agents for polymer chemistry and as starting compounds in synthetic chemistry.<smiles>[X]c1c([X])c(C#N)c([X])c([X])c1C#N</smiles>

87a: $\mathrm{X}=\mathrm{Cl}$

87b: $\mathrm{X}=\mathrm{Br}$

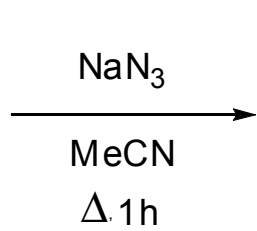

$95 \%$ yield from $87 a$ $78 \%$ yield from $\mathbf{8 7 b}$<smiles>N#Cc1c(N)c(C#N)c(N)c(C#N)c1N</smiles>

88<smiles>O=[N+]([O-])c1c(Cl)c(S(=O)(=O)OC(F)(F)F)c(Cl)c(S(=O)(=O)OC(F)(F)F)c1Cl</smiles>

89<smiles>CC(C)=NCc1ccccc1</smiles>

99\% yield<smiles>Nc1c([N+](=O)[O-])c(N)c(S(=O)(=O)OC(F)(F)F)c(N)c1[N+](=O)[O-]</smiles>

90<smiles>[X]c1c(F)c([X])c(F)c([X])c1F</smiles>

91a: $X=Y=C l$ 91b: $X=Y=B r$ 91c: $X=\mathrm{Cl}, Y=\mathrm{Br}$<smiles>[X]c1c(N)c([X])c(N)c([Y])c1N</smiles>

92a $(98 \%)$

92b $(81 \%)$

92c $(88 \%)$<smiles>Nc1c(Br)c(N)c(Br)c(F)c1Br</smiles>

$93(15 \%)$

Scheme 24. Synthesis of triazides 88,90 and $92 a-c$.

The most contradictory data were reported on the synthesis and properties of triazide 94. In 1967, Breslow and Marcantonio patented the preparation of 94, based on diazotization of triamine 95 (Scheme 25) [131]. However, neither the protocol of preparation nor the yield and melting point of $\mathbf{9 4}$ were reported. Later, Kim and Lee have described the preparation of 94 by azidation of ester 96 in boiling dioxane [132]. Again, neither the yield nor melting point of $\mathbf{9 4}$ was reported. It was just mentioned that NMR spectra of triazide 94 display a signal of protons at $\delta 7.30 \mathrm{ppm}$ and a signal of carbons at $\delta 128.0 \mathrm{ppm}$. Very recently, the synthesis of triazide 94 from various precursors has been investigated by Juriček [133]. He found that triamine 95 is very unstable in acidic media and cannot be converted in triazide $\mathbf{9 4}$, using the diazotization reaction. The highest yield (26\%) of triazide 94 was achieved in the reaction of tribromobenzene 97 with $n$-butyllithium followed by the diazo-transfer reaction from tosylazide to intermediate trilithiobenzene (Scheme 25). The stepwise treatment of triamine 95 at first with $n$-butyllithium and then with $\left(\mathrm{Et}_{2} \mathrm{~N}\right)_{3} \mathrm{PN}_{3} \cdot \mathrm{PF}_{6}$ salt as a diazo-transfer reagent gave triazide 94 in 25\% yield (Scheme 25) [133]. Triazide 94 was obtained as a yellow solid that was insensitive toward impact and friction. NMR spectra of triazide $\mathbf{9 4}$ displayed 
a signal of protons at $\delta 6.45 \mathrm{ppm}$ and two signals of carbon atoms at $\delta 106.1(\mathrm{CH})$ and $143.2\left(\mathrm{C}-\mathrm{N}_{3}\right) \mathrm{ppm}$. These spectroscopic characteristics agreed well with ${ }^{1} \mathrm{H}$ - and ${ }^{13} \mathrm{C}-\mathrm{NMR}$ spectra of triazide 99 obtained in $42 \%$ yield by diazotization of triamine 98 (Scheme 25) [24]. Similarly to triazide 94, triazide 99 was obtained as a yellow solid with a melting point of 103-104 ${ }^{\circ} \mathrm{C}$. NMR spectra of triazide 99 displayed two signals of protons at $\delta 1.93(\mathrm{Me})$ and $6.48(\mathrm{CH}) \mathrm{ppm}$ and four signals of carbon atoms at $\delta 10.0$ (Me), $103.8(\mathrm{CH}), 117.2(\mathrm{C}-\mathrm{Me}), 138.4\left(\mathrm{C}_{4}-\mathrm{N}_{3}\right)$ and $140.3\left(\mathrm{C}_{2,6}-\mathrm{N}_{3}\right) \mathrm{ppm}$. Similarly to triazide 94, triazide $\mathbf{9 9}$ is also insensitive toward impact and friction. Both triazides 94 and 99 are efficient cross-linking agents for polymer chemistry [131,134]. These triazides are also promising starting materials for supramolecular chemistry. Thus, the copper-catalyzed azide-alkyne cycloadditions (CuAAC- or click-reactions) of triazide 94 with acetylenes 100, 102 and 104 afforded tris-adducts 101, 103 and 105 (Scheme 26) [133]. The more unpredictable reaction of triazide 94 with tris-acetylene 106 gave tris-adduct 107 in just 30\% yield (Scheme 27) [133]. The latter can be obtained in $99 \%$ yield by alkali hydrolysis of tris-adduct 105 [133]. Both hexaacetylenes 105 and $\mathbf{1 0 7}$ possess a huge synthetic potential and are of considerable interest as building-blocks for synthetic chemistry.
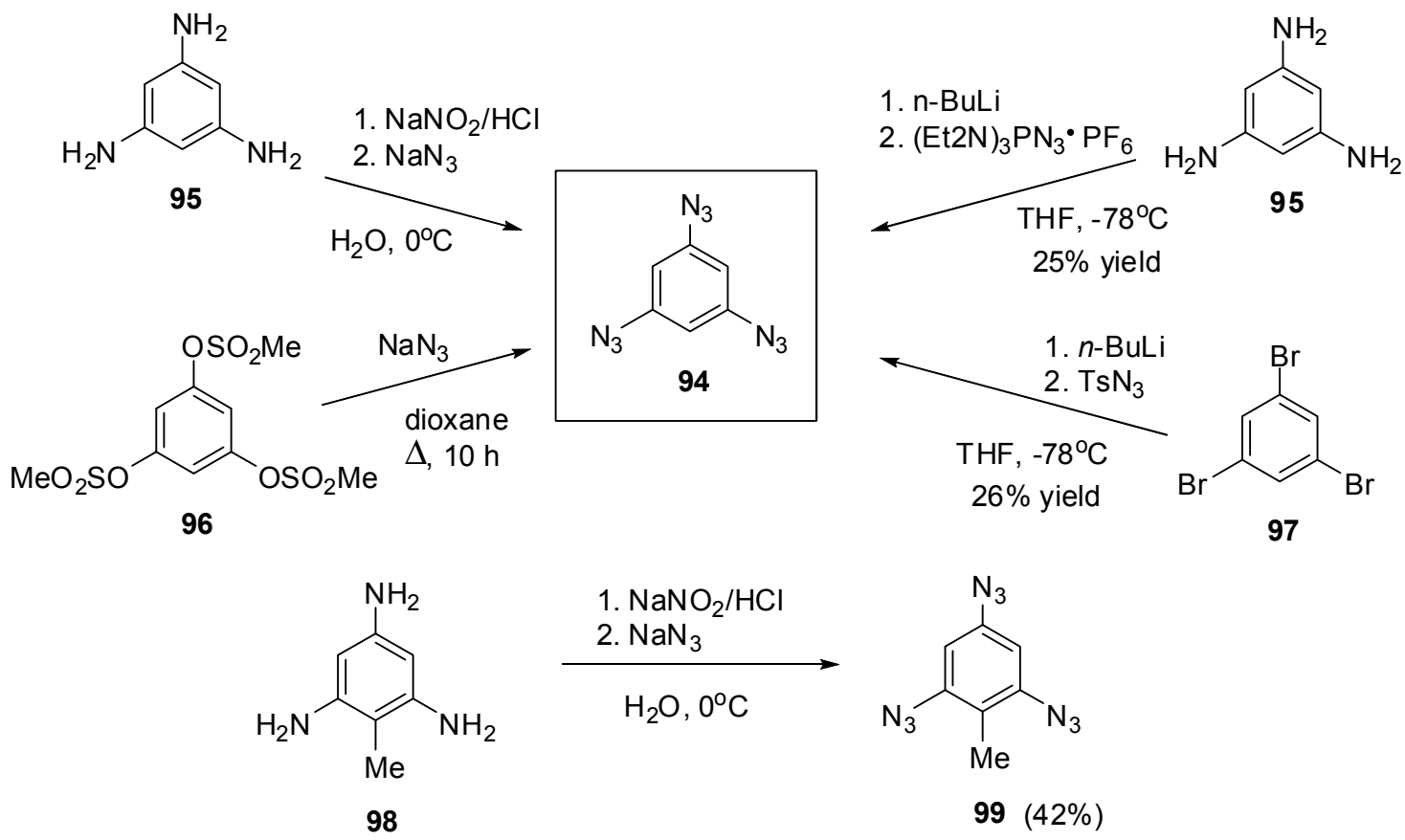

Scheme 25. Synthesis of triazides 94 and 99.

Recent X-ray diffraction studies have shown that the azido groups of triazides $\mathbf{8 1}$ and $\mathbf{8 8}$ are rotated out of the $\mathrm{C}_{6}$ plane in order to reduce steric repulsion [124,128]. Due to this effect, all three azido groups of $\mathbf{8 1}$ and $\mathbf{8 8}$ are structurally nonequivalent and slightly differ in the $\mathrm{C}-\mathrm{N} \alpha, \mathrm{N} \alpha-\mathrm{N} \beta$ and $\mathrm{N} \beta-\mathrm{N} \gamma$ bond distances and the $\mathrm{C}-\mathrm{N} \alpha-\mathrm{N} \beta$ and $\mathrm{N} \alpha-\mathrm{N} \beta-\mathrm{N} \gamma$ angles. These parameters of triazides $\mathbf{8 1}$ and $\mathbf{8 8}$ are very close to that of the $\gamma$-azido groups of triazidopyridines 55b and 55c [102-104]. It is therefore not surprising that the $\gamma$-azido groups of triazidopyridines $\mathbf{5 5 b}$ and $\mathbf{5 5 c}$ and the azido groups of triazides $\mathbf{9 2 a}$ and 92b display similar chemical shifts in ${ }^{15} \mathrm{~N}-\mathrm{NMR}$ spectra $[73,130]$. In ${ }^{13} \mathrm{C}-\mathrm{NMR}$ spectra of $D_{3 \mathrm{~h}}$ symmetric triazides $\mathbf{8 8}, \mathbf{9 2 a}, \mathbf{9 2 b}$ and 94 , the signals of the $\mathrm{C}-\mathrm{N}_{3}$ atoms are the most deshielded and manifested in the $\delta 134-150$ ppm region, while the signals of the $\mathrm{C}-\mathrm{R}$ atoms are usually observed in the $\delta$ 95-122 ppm region [128,130,133]. 


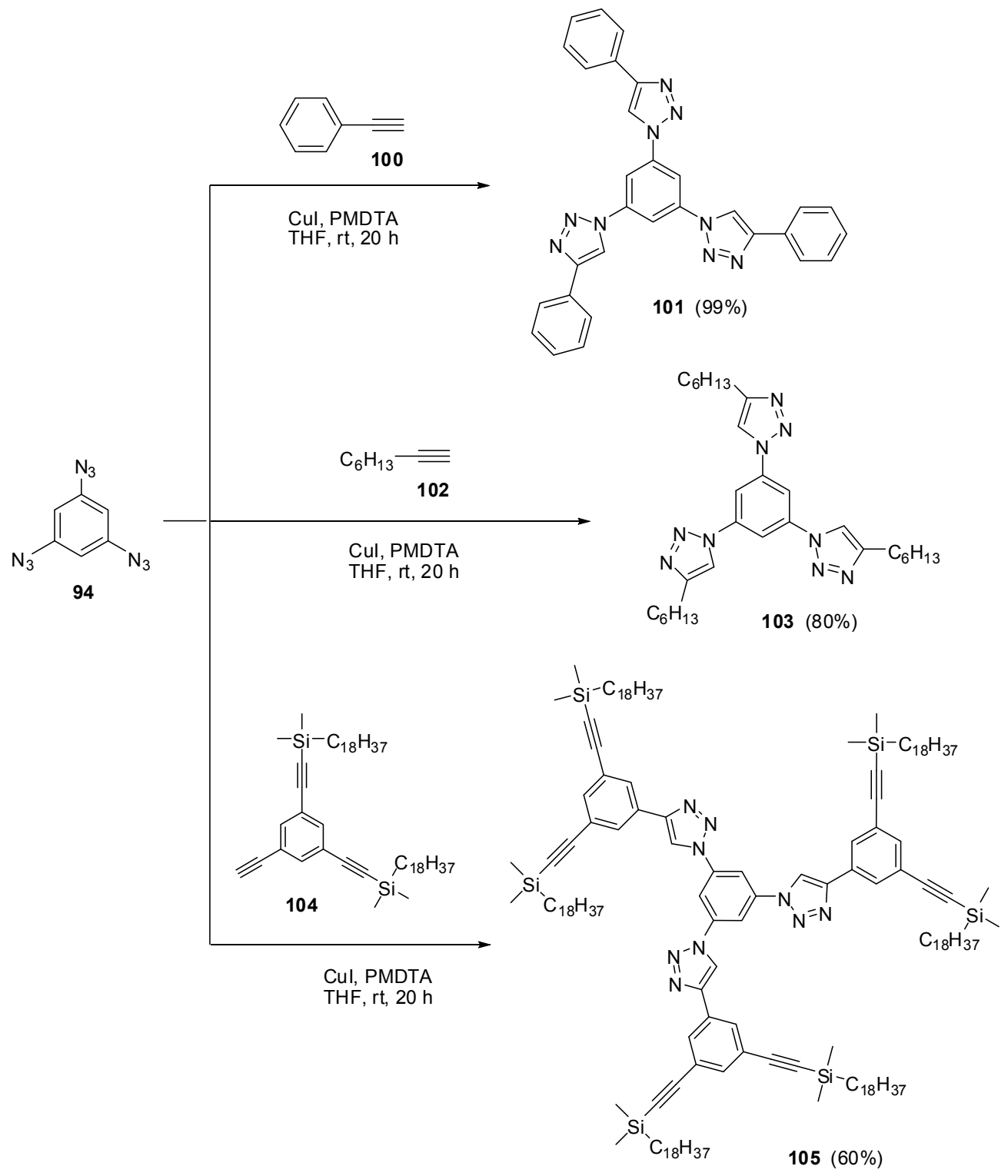

Scheme 26. Some click-reactions of triazide 94.

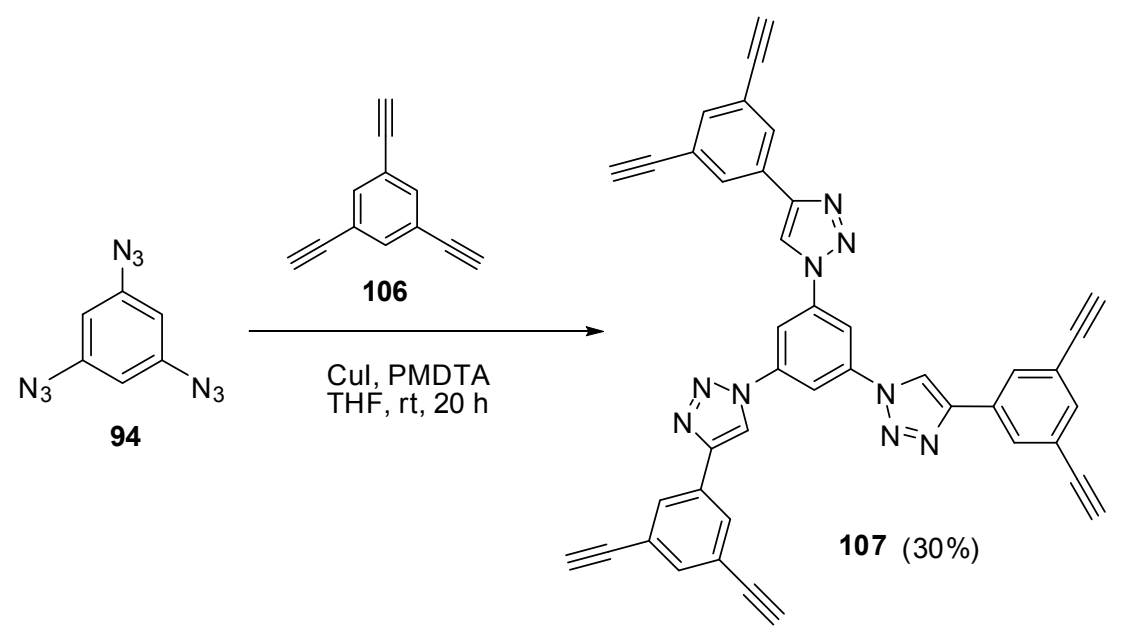

Scheme 27. Click-reaction of triazide 94 with tris-acetylene 106. 
Triazides 88, 92a-c and 99 have played a historical role in investigations of high-spin organic molecules. Trinitrene 108 obtained by the photolysis of triazide $\mathbf{8 8}$ in frozen organic solutions became the first organic septet hexaradical that was detected with X-band EPR spectroscopy (Scheme 28) [10]. Based on intuitive assignment of signals in EPR spectrum, the magnetic parameter $D \approx-0.055 \mathrm{~cm}^{-1}$ of trinitrene 108 was calculated. For many years, this value of $D$ served as a benchmark in investigations of many other high-spin organic molecules [117]. Only recently, owing to the appearance of modern computer line-shape EPR spectral simulation programs, it was established that trinitrene 108 has $D=-0.092 \mathrm{~cm}^{-1}$ [29]. Similar values of $D$ were also determined for trinitrenes $109\left(D=-0.0934 \mathrm{~cm}^{-1}\right)$ and $110\left(D=-0.0957 \mathrm{~cm}^{-1}\right)$ obtained by the photolysis of triazides 99 and 92a, respectively [24,29]. These studies showed that septet 1,3,5-trinitrenobenzenes have relatively low spin densities on the nitrene units and, as a result, relatively weak dipolar spin-spin interactions and magnetic properties among septet trinitrenes. On the other hand, the introduction of heavy atoms in positions 2, 4 and 6 of septet 1,3,5-trinitrenobenzenes allows the preparation of organic hexaradicals possessing the record values of magnetic anisotropy. Thus, trinitrene 111 obtained by the photolysis of triazide $92 \mathbf{b}$ shows $D=-0.203 \mathrm{~cm}^{-1}$ [33]. In such molecules, the large negative value of $D$ arises due to very strong anisotropic spin-orbit interactions. As a result, the $D$ value of trinitrene 111 exceeds almost two times the $D$ value of septet 2,4,6-trinitreno-s-triazine 17 (see Scheme 5) possessing the strongest dipolar spin-spin interactions among septet trinitrenes. Photochemical studies of triazidobenzenes provide also important information about the effect of subtle structural changes in the molecules of these compounds on magnetic properties of organic polyradicals. Thus, it was found that, in contrast to trinitrenes $108,109,110$ and 111 , trinitrene 112 has a positive sign of $D=0.124 \mathrm{~cm}^{-1}$ and does not possess the magnetism [32]. Since the presence of only one heavy bromine atom in the molecule, the principal magnetic Z-axis of trinitrene 112 lies in the molecular plane perpendicularly to the $\mathrm{C}-\mathrm{Br}$ bond, and the principal values $D_{\mathrm{xx}}, D_{\mathrm{yy}}$ and $D_{\mathrm{zz}}$ of the total tensor $\mathbf{D}$ have such magnitudes and signs for which the total parameter $D$ is large in magnitude and positive in sign. Another unexpected result was obtained during W-band EPR studies of quintet dinitrene 113 formed in the photolysis of triazide 92b [33]. In contrast to all known quintet dinitrenes, dinitrene 113 showed negative sign of $D=-0.306 \mathrm{~cm}^{-1}$ due to the effect of three heavy bromine atoms.<smiles>[N]c1c(N)c(C#N)c(C#N)c(N)c1C#N</smiles>

108<smiles>CNc1cc(N)cc(N)c1N</smiles>

109<smiles>CNc1c(N)c(N)c(Cl)c(N)c1Cl</smiles>

110<smiles>CNc1c(Br)c(N=N)c(Br)c(NC)c1Br</smiles>

111<smiles>CNc1c(Cl)c([NH])c(Cl)c(NC)c1Br</smiles>

112<smiles>CNc1c(Br)c(N)c(Br)c(NC)c1Br</smiles>

113

Scheme 28. High-spin nitrenes obtained by photolysis of triazides $\mathbf{8 8}, \mathbf{9 2 a}-\mathbf{c}$ and 99 . 


\section{Tetraazides}

Six-membered aromatic tetraazides represent one of the least studied classes of organic compounds. To the moment, the synthesis of only four such tetraazides has been reported, and only one of them was characterized with modern spectroscopic methods. The first representative of six-membered aromatic tetraazides, 1,2,4,5-tetrazido-3,6-dihydroxybenzene (115), was prepared by Sorm in 1939, using the reduction of tetraazidoquinone $\mathbf{1 1 4}$ with potassium iodide in acidic media (Scheme 29) [135]. During this reaction, deep-blue quinone $\mathbf{1 1 4}$ was turned into hydroquinone $\mathbf{1 1 5}$ as insoluble in water white solid. The latter was metastable in the air and quickly oxidized to the starting quinone 114. On comparison with very sensitive tetraazidoquinone 114, tetraazidohydroquinone 115 was much less sensitive to impact, friction and spark. The second representative of this class of compounds, tetrazidophthalic acid 117, was prepared in 95\% yield by the reaction of tetrachlorophthalic anhydride $\mathbf{1 1 6}$ with sodium azide in dimethylsulfoxide at room temperature (Scheme 29) [136]. Tetraazide 117 was obtained as a white solid with a melting point of $113^{\circ} \mathrm{C}$. Since its very high sensitivity to mechanical stimuli, no any further studies of 117 were carried out. Finally, Pannell in 1975 has reported the synthesis of tetraazide 119 by the reaction of tetrachloride 118 with sodium azide in dimethylformamide at $80{ }^{\circ} \mathrm{C}$ (Scheme 29) [137,138]. Recently, this tetraazide was obtained by azidation of tetrachloride 118 with sodium azide in aqueous acetone at room temperature in $96 \%$ yield [91].<smiles>NC1=C(N)C(=O)C(N)=C(N)C1=O</smiles>

114<smiles>O=C1OC(=O)c2c(Cl)c(Cl)c(Cl)c(Cl)c21</smiles>

116<smiles>N#Cc1nc(Cl)c(Cl)c(Cl)c1Cl</smiles>

118
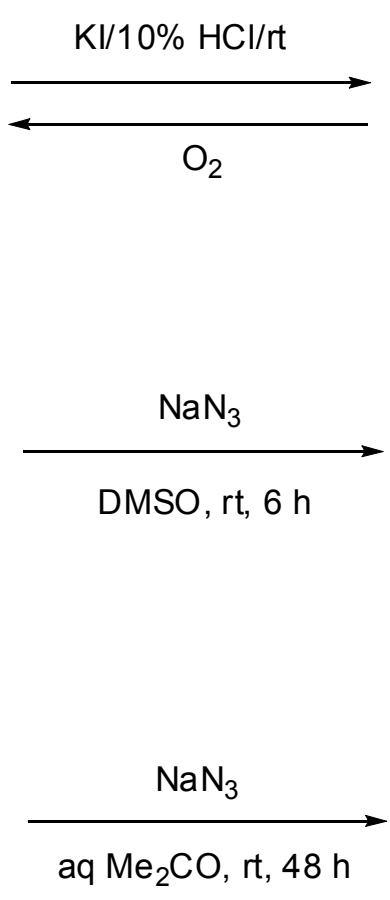

aq $\mathrm{Me}_{2} \mathrm{CO}, \mathrm{rt}, 48 \mathrm{~h}$<smiles>N#[N+]c1c(O)c([N+]#N)c(O)c([N+]#N)c1O</smiles>

115<smiles>Nc1c(N)c(N)c(C(=O)O)c(C(=O)O)c1N</smiles><smiles>N#Cc1nc(N)c(N)c(N)c1N</smiles>

$119(96 \%)$

Scheme 29. Synthesis of tetraazides 115, 117 and 119.

On crystallization from ethanol, tetraazide $\mathbf{1 1 9}$ is obtained as a brown solid with a melting point of $103{ }^{\circ} \mathrm{C}$ [92]. This tetraazide is very sensitive to impact and friction and violently explodes on quick heating at $23{ }^{\circ} \mathrm{C}$. On working with it, one should always handle 119 only with plastic spatulas and use thick gloves 
behind a blast shield. Due to interatomic interactions of the neighboring azido groups in the molecule, the rate of the thermal decomposition of 119 is 1000 times higher than that of 2,4,6-triazido-3,5dicyanopyridine (55c) [139]. Most likely, the thermal decomposition of $\mathbf{1 1 9}$ follows the chain-mechanism, yielding molecular nitrogen and $\mathrm{C}_{3} \mathrm{~N}_{4}$ carbon nitrides as the final products. The IR and UV spectra of tetraazide 119 are very similar to those of triazide 55c [92]. The ${ }^{13} \mathrm{C}-\mathrm{NMR}$ spectrum of tetraazide 119 shows six signals of the carbon atoms at $\delta 113.4(\mathrm{CN}), 118.2$ (C-6), 122.8 (C-3), 129.7 (C-5), 133.1 (C-4) and $145.1 \mathrm{ppm}(\mathrm{C}-2)$ [91].

To the moment, nothing is known about the properties of six-membered aromatic compounds with five and six azido groups in the ring. It has just been reported that azidation of hexafluorobenzene (120) with sodium azide in hot dimethylsulfoxide led to the formation of a mixture of diazide $\mathbf{1 2 1}$ and tetraazide $\mathbf{1 2 2}$ as the major products as well as hexaazide 123 as a minor product (Scheme 30) [140]. However, during the next five decades, no any other information on the synthesis, properties and use of tetraazide 122 and hexaazide $\mathbf{1 2 3}$ appeared in the literature. So far, hexaazide $\mathbf{1 2 3}$ as well as pentaazidopyridine and tetraazidopyrimidine can be considered only as hypothetical molecules in theoretical studies [141-143].<smiles>Nc1c(N)c(N)c(N)c(N)c1N</smiles>

Scheme 30. Azidation of hexafluorobenzene 120.

\section{Summary}

Of the twenty five six-membered aromatic triazides known to date, eighteen have been synthesized and spectrally characterized only in the last two decades. Many of these triazides are prepared in one step and in high yield from commercially available starting halides. Moreover, most of these triazides are rather safety compounds and can explode only under very specific conditions. Owing to these features, six-membered aromatic triazides may be of considerable interest as starting materials for synthetic chemistry and photochemistry as well as cross-linking agents for polymer chemistry and microelectronics. The high antitumor activity of 2,4,6-triazidopyrimidine against Sarcoma 180, Piss lymphosarcoma and Guerin carcinoma indicates that some of aromatic triazides may possess interesting biological properties. However, the most promising application of aromatic triazides may be their use as starting materials in click-chemistry aimed at the design of new polyfunctional supramolecular systems possessing useful chemical, physical and biological properties. Thus, for instance, just the successive cycloaddition of different acetylenes to such triazides already provides unique opportunities to synthesize a great variety of new organic compounds, using relatively simple experimental procedures.

\section{Conflicts of Interest}

The author declares no conflict of interest. 


\section{References}

1. Sutton, T.C. Structure of cyanuric triazide, $\left(\mathrm{C}_{3} \mathrm{~N}_{3}\right)\left(\mathrm{N}_{3}\right)_{3}$. Philos. Mag. 1933, 15, 1001-1018.

2. Bragg, W.H. Structure of the azide group [crystal structure of cyanuric triazide]. Nature 1934, $134,138$.

3. Hughes, E.W. Crystal structure of cyanuric triazide. J. Chem. Phys. 1935, 3, 1-5.

4. Knaggs, J.E. Structure of cyanuric triazide. J. Chem. Phys. 1935, 3, 241.

5. Knaggs, E. The crystal structure of cyanuric triazide. Proc. Roy. Sci. Lond. 1935, 150, 576-602.

6. Kroke, E.; Schwarz, M.; Buschmann, V.; Miehe, G.; Fuess, H.; Riedel, R. Nanotubes formed by detonation of C/N precursors. Adv. Mater. 1999, 11, 158-161.

7. Gillan, E.G. Synthesis of nitrogen-rich carbon nitride networks from an energetic molecular azide precursor. Chem. Mater. 2000, 12, 3906-3912.

8. Wang, J.; Gillan, E.G. Low-temperature deposition of carbon nitride films from a molecular azide, $\left(\mathrm{C}_{3} \mathrm{~N}_{3}\right)\left(\mathrm{N}_{3}\right)_{3}$. Thin Solid Films 2002, 422, 62-68.

9. Utschig, T.; Schwarz, M.; Miehe, G.; Kroke, E. Synthesis of carbon nanotubes by detonation of 2,4,6-triazido-1,3,5-triazine in the presence of transition metals. Carbon 2004, 42, 823-828.

10. Wasserman, E.; Schueller, K.; Yager, W.A. EPR detection of the septet ground state of a trinitrene. Chem. Phys. Lett. 1968, 2, 259-260.

11. Chapyshev, S.V.; Kuhn, A.; Wong, M.W.; Wentrup, C. Mono-, di- and trinitrenes in the pyridine series. J. Am. Chem. Soc. 2000, 122, 1572-1579.

12. Chapyshev, S.V.; Walton, R.; Sanborn, J.A.; Lahti, P.M. Quintet and septet state systems based on pyridylnitrenes: Effect of substitution on open-shell high-spin states. J. Am. Chem. Soc. 2000, 122, 1580-1588.

13. Chapyshev, S.V. Electronic absorption spectra of quintet and septet pyridylnitrenes. Mendeleev Commun. 2002, 12, 168-170.

14. Sato, T.; Narazaki, A.; Kawaguchi, Y.; Niino, H.; Bucher, G. Dicyanocarbodiimide and trinitreno$s$-triazine generated by consecutive photolysis of triazido-s-triazine in a low-temperature nitrogen matrix. Angew. Chem. Int. Ed. 2003, 42, 5206-5209.

15. Sato, T.; Narazaki, A.; Kawaguchi, Y.; Niino, H.; Bucher, G.; Grote, D.; Wolff, J.J.; Wenk, H.H.; Sander, W. Generation and photoreactions of 2,4,6-trinitreno-1,3,5-triazine, a septet trinitrene. J. Am. Chem. Soc. 2004, 126, 7846-7852.

16. Kuzina, S.I.; Mikhailov, A.I.; Chapyshev, S.V. Radiolysis and photolysis of crystalline 2,4,6-triazido-3,5-dichloropyridine: Generation of quintet dinitrenes. High Energy Chem. 2007, $41,245-250$.

17. Kuzina, S.I.; Mikhailov, A.I.; Chapyshev, S.V. Effect of microwave radiation on the magnetic properties of quintet dinitrenes. Dokl. Phys. Chem. 2007, 412, 34-37.

18. Morgunov, R.B.; Berdinskii, V.L.; Kirman, M.V.; Tanimoto, Y.; Chapyshev, S.V. Photochemical magnetism of crystalline 2,4,6-triazido-3,5-dichloropyridine. High Energy Chem. 2007, 41, 33-36.

19. Chapyshev, S.V.; Kuzina, S.I.; Mikhailov, A.I. Generation of quintet dinitrenes by $\gamma$-radiolysis of crystalline 2,4,6-triazido-3,5-dicyanopyridine. Mendeleev Commun. 2007, 17, 207-208.

20. Chapyshev, S.V.; Grote, D.; Finke, C.; Sander, W. Matrix isolation and EPR spectroscopy of septet 3,5-difluoropyridyl-2,4,6-trinitrene. J. Org. Chem. 2008, 73, 7045-7051. 
21. Misochko, E.Y.; Akimov, A.V.; Chapyshev, S.V. High resolution EPR spectroscopy of septet 3,5-dichloropyridyl-2,4,6-trinitrene in solid argon. Fine-structure parameters of six electron-spin cluster. J. Chem. Phys. 2008, 129, 174510, doi:10.1063/1.3005378.

22. Chapyshev, S.V.; Neuhaus, P.; Grote, D.; Sander, W. Matrix isolation and magnetic parameters of septet 3,5-dicyanopyridyl-2,4,6-trinitrene. J. Phys. Org. Chem. 2010, 23, 340-346.

23. Chapyshev, S.V.; Korchagin, D.V.; Neuhaus, P.; Sander, W. High-spin intermediates of the photolysis of 2,4,6-triazido-3-chloro-5-fluoropyridine. Beilstein J. Org. Chem. 2013, 9, 733-742.

24. Chapyshev, S.V.; Misochko, E.Y.; Akimov, A.V.; Dorokhov, V.G.; Neuhaus, P.; Grote, D.; Sander, W. Molecular structure and magnetic parameters of septet 2,4,6-trinitrenotoluene. J. Org. Chem. 2009, 74, 7238-7244.

25. Misochko, E.Y.; Korchagin, D.V.; Bozhenko, K.V.; Chapyshev, S.V.; Aldoshin, S.M. A density functional theory study of the zero-field splitting in high-spin nitrenes. J. Chem. Phys. 2010, 133, 064101, doi:10.1063/1.3474574.

26. Misochko, E.Y.; Akimov, A.V.; Masitov, A.A.; Korchagin, D.V.; Yakushchenko, I.K.; Chapyshev, S.V. High-spin organic molecules with dominant spin-orbit contribution and unprecedentedly large magnetic anisotropy. J. Chem. Phys. 2012, 137, 064308, doi:10.1063/1.4742342.

27. Misochko, E.Y.; Akimov, A.V.; Mazitov, A.A.; Korchagin, D.V.; Chapyshev, S.V. Magnetic anisotropy parameters of matrix-isolated septet 1,3,5-trinitreno-2,4,6-trichlorobenzene. Russ. Chem. Bull. 2012, 61, 2218-2224.

28. Kuzina, S.I.; Tokarev, S.V.; Korchagin, D.V.; Kolpakov, G.A.; Khudyakov, D.V.; Chapyshev, S.V.; Mikhailov, A.I.; Nadtochenko, V.A.; Aldoshin, S.M. Molecular magnetic structures based on high-spin intermediates of low-temperature radiolysis of azido derivatives and possibilities of their use in undulator systems. Russ. Chem. Bull. 2013, 62, 255-264.

29. Misochko, E.Y.; Akimov, A.V.; Masitov, A.A.; Korchagin, D.V.; Aldoshin, S.M.; Chapyshev, S.V. Matrix isolation ESR spectroscopy and magnetic anisotropy of $D_{3 \mathrm{~h}}$ symmetric septet trinitrenes. J. Chem. Phys. 2013, 138, 204317, doi:10.1063/1.4807608.

30. Chapyshev, S.V.; Ushakov, E.N.; Neuhaus, P.; Sander W. Matrix isolation, zero-field splitting parameters, and photoreactions of 2,4,6-trinitrenopyrimidines. J. Org. Chem. 2014, 79, 6047-6053.

31. Misochko, E.Y.; Akimov, A.V.; Mazitov, A.A.; Korchagin, D.V.; Chapyshev, S.V. Magnetic anisotropy parameters of matrix-isolated septet 1,3,5-trinitreno-2,4,6-tribromobenzene. Russ. Chem. Bull. 2015, 64, 87-91.

32. Misochko, E.Y.; Masitov, A.A.; Akimov, A.V.; Korchagin, D.V.; Chapyshev, S.V. Heavy atom effect on magnetic anisotropy of matrix-isolated monobromine substituted septet trinitrene. J. Phys. Chem. A 2015, 119, 2413-2419.

33. Akimov, A.; Masitov, A.; Korchagin, D.; Chapyshev, S.; Misochko, E.; Savitsky, A. W-band EPR studies of high-spin nitrenes with large spin-orbit contribution to zero-field splitting. J. Chem. Phys. 2015, 143, 084313, doi:10.1063/1.4929589.

34. Chapyshev, S.V. Selective reactions on the azido groups of aromatic polyazides. Synlett 2009, 2009, 1-8, doi:10.1055/s-0028-1087479.

35. Chapyshev, S.V. Aromatic polyazides and high-spin nitrenes. Russ. Chem. Bull. 2011, 60, 1274-1285.

36. Bräse, S.; Gil, C.; Knepper, K.; Zimmermann, V. Organic azides: An exploding diversity of a unique class of compounds. Angew. Chem. Int. Ed. 2005, 44, 5188-5240. 
37. Schilling, C.; Jung, N.; Bräse, S. Cycloaddition reactions with azides: An overview. In Organic Azides: Synthesis and Applications; Bräse, S., Banert, K., Eds.; Wiley: Chichester, UK, 2010; pp. 269-284.

38. Juwarker, H.; Lenhardt, J.M.; Pham, D.M.; Craig, S.L. 1,2,3-Triazole CH ${ }^{\cdots}$ Cl- contacts guide anion binding and concomitant folding in 1,4-diaryl triazole oligomers. Angew. Chem. Int. Ed. 2008, 47, 3740-3743.

39. Meudtner, R.M.; Hecht, S. Helicity inversion in responsive foldamers induced by achiral halide ion guests. Angew. Chem. Int. Ed. 2008, 47, 4926-4930.

40. Li, Y.; Flood, A.H. Strong, Size-selective, and electronically tunable C-H $\cdots$ Halide binding with steric control over aggregation from synthetically modular, shape-persistent[34]triazolophanes. J. Am. Chem. Soc. 2008, 130, 12111-12122.

41. Megiatto, J.D., Jr.; Schuster, D.I. General method for synthesis of functionalized macrocycles and catenanes utilizing "click" chemistry. J. Am. Chem. Soc. 2008, 130, 12872-12873.

42. Li, Y.; Pink, M.; Karty, J.A.; Flood, A.H. Dipole-promoted and size-dependent cooperativity between pyridyl-containing triazolophanes and halides leads to persistent sandwich complexes with iodide. J. Am. Chem. Soc. 2008, 130, 17293-17295.

43. Juwarker, H.; Lenhardt, J.M.; Castillo, J.C.; Zhao, E.; Krishnamurthy, S.; Jamiolkowski, R.M.; Kim, K.; Craig, S.L. Anion binding of short, flexible aryl triazole oligomers. J. Org. Chem. 2009, 74, 8924-8934.

44. Latyshev, G.V.; Baranov, M.S.; Kazantsev, A.V.; Averin, A.D.; Lukashev, N.V.; Beletskaya, I.P. Copper-catalyzed [1,3]-dipolar cycloaddition for the synthesis of macrocycles containing acyclic, aromatic and steroidal moieties. Synthesis 2009, 41, 2605-2615.

45. Zheng, L.; Huang, X.; Shen, Y.; Cheng, Y. Click chemistry approach to fluorescence-based polybinaphthyls incorporating a triazole moiety for $\mathrm{Hg}^{2+}$ recognition. Synlett 2010, 2010, 453-456.

46. Huang, X.; Dong, Y.; Meng, J.; Cheng, Y.; Zhu, C. Fluorescence polymer incorporating triazole and benzo[2,1,3]thiadiazole moieties for $\mathrm{Ni}^{2+}$ detection. Synlett 2010, 2010, 1841-1844.

47. Hua, Y.; Flood, A.H. Flipping the switch on chloride concentrations with a light-active foldamer. J. Am. Chem. Soc. 2010, 132, 12838-12840.

48. Megiatto, J.D., Jr.; Schuster, D.I. Introduction of useful peripheral functional groups on [2]catenanes by combining $\mathrm{Cu}(\mathrm{I})$ template synthesis with "click" chemistry. New J. Chem. 2010, 34, 276-286.

49. Juricek, M.; Felici, M.; Contreras-Carballada, P.; Lauko, J.; Bou, S.R.; Kouwer, P.H.J.; Brouwer, A.M.; Rowan, A.E. Triazole-pyridine ligands: A novel approach to chromophoric iridium arrays. J. Mater. Chem. 2011, 21, 2104-2111.

50. Plietzsch, O.; Schilling, C.I.; Grab, T.; Grage, S.L.; Ulrich, A.S.; Comotti, A.; Sozzani, P.; Muller, T.; Brase, S. Click chemistry produces hyper-cross-linked polymers with tetrahedral cores. New J. Chem. 2011, 35, 1577-1581.

51. Zornik, D.; Meudtner, R.M.; El Malah, T.; Thiele, C.M.; Hecht, S. Designing structural motifs for clickamers: Exploiting the 1,2,3-triazole moiety to generate conformationally restricted molecular architectures. Chem. Eur. J. 2011, 17, 1473-1484.

52. Wu, Y.; Dong, Y.; Li, J.; Huang, X.; Cheng, Y.; Zhu, C. A Highly selective and sensitive polymer-based fluorescence sensor for $\mathrm{Hg}^{2+}$-ion detection via click reaction. Chem. Asian J. 2011, $6,2725-2729$. 
53. Hajipour, A.R.; Abrishami, F. Synthesis and characterization of novel polyimides containing triazoles units in the main chain by click chemistry. J. Appl. Polym. Chem. 2012, 124, 1757-1763.

54. You, L.; Chen, S.; Zhao, X.; Liu, Y.; Lan, W.; Zhang, Y.; Lu, H.; Cao, C.; Li, Z. C-H $\cdots$ O hydrogen bonding induced triazole foldamers: Efficient halogen bonding receptors for organohalogens. Angew. Chem. Int. Ed. 2012, 51, 1657-1661.

55. Hua, Y.; Liu, Y.; Chen, C.; Flood, A.H. Hydrophobic collapse of foldamer capsules drives picomolar-level chloride binding in aqueous acetonitrile solutions. J. Am. Chem. Soc. 2013, 135, 14401-14412.

56. Merckx, T.; Verwilst, P.; Dehaen, W. Preorganization in bistriazolyl anion receptors. Tetrahedron Lett. 2013, 54, 4237-4240.

57. Wu, C.; Li, Z.; Xu, X.; Zhao, Z.; Zhao, X.; Wang, R.; Li, Z. Folding-induced folding: The assembly of aromatic amide and 1,2,3-triazole hybrid helices. Chem. Eur. J. 2014, 20, 1418-1426.

58. Shang, J.; Gallagher, N.M.; Bie, F.; Li, Q.; Che, Y.; Wang, Y.; Jiang, H. Aromatic triazole foldamers induced by $\mathrm{C}-\mathrm{H} \cdots \mathrm{X}(\mathrm{X}=\mathrm{F}, \mathrm{Cl})$ intramolecular hydrogen bonding. J. Org. Chem. 2014, 79, 5134-5144.

59. Lee, S.; Hua, Y.; Flood, A.H. $\beta$-Sheet-like hydrogen bonds interlock the helical turns of a photoswitchable foldamer to enhance the binding and release of chloride. J. Org. Chem. 2014, 79, 8383-8396.

60. Merckx, T.; Haynes, C.J.E.; Karagiannidis, L.E.; Clarke, H.J.; Holder, K.; Kelly, A.; Tizzard, G.J.; Coles, S.J.; Verwilst, P.; Gale, P.A.; et al. Anion binding and transport properties of cyclic 2,6-bis(1,2,3-triazol-1-yl)pyridines. Org. Biomol. Chem. 2015, 13, 1654-1661.

61. Finger, H. Über Abkömmlinge des Cyanurs. J. Prakt. Chem. 1907, 75, 103-104.

62. Ott, E.; Ohse, E. Zur kenntnis einfachen Cyan- und Cyanurverbindungen. II. Über das Cyanurtriazid $\left(\mathrm{C}_{3} \mathrm{~N}_{12}\right)$. Ber. Dtsch. Chem. Ges. 1921, 54B, 179-186.

63. Keßenich, E.; Klapötke, T.M.; Knitzek, J.; Nöth, H.; Schultz, A. Characterization, crystal structure of 2,4-bis(triphenylphosphanimino)tetrazolo[5,1-a]-[1,3,5]triazine, and improved crystal structure of 2,4,6-triazido-1,3,5-triazine. Eur. J. Inorg. Chem. 1998, 1998, 2013-2016.

64. Kessenich, E.; Polborn, K.; Schultz, A. Reaction of 2,4,6-triazido-1,3,5-triazine with triphenylphosphane. Synthesis and characterization of the novel 2-triphenylphosphanimino-4-azidotetrazolo[5,1-a][1,3,5]triazine and 2,4,6-tris(triphenylphosphanimino)-1,3,5-triazine. Inorg. Chem. 2001, 40, 1102-1109.

65. Hart, C.V. Carbonic acid azides. J. Am. Chem. Soc. 1928, 50, 1922-1930.

66. Allschwil, E.N.; Stein, L.E. Azido-1,3,5-triazines. Patent NL 6413689, 28 May 1965.

67. Beck, W.; Bauder, M. Reactions of hydridoplatinum(II) complexes with organic azides: Amido complexes. Chem. Ber. 1970, 103, 583-589.

68. Pochinok, V.Y.; Avramenko, L.F.; Grigorenko, T.F.; Pochinok, A.V.; Sidorenko, I.A.; Bovchalyuk, L.N. Synthesis of 2,4,6-triazidopyrimidine, 2,4,6-triazido-s-triazine, and triazenes produced from them. Ukr. Khim. Zh. 1979, 45, 975-978.

69. Thust, R.; Schneider, M.; Wagner, U.; Schreiber, D. Structure/activity investigations in eight arylalkyltriazenes comparison of chemical stability mode of decomposition and SCE induction in Chinese hamster V79-E cells. Cell Biol. Toxicol. 1991, 7, 145-165.

70. Eggermont, A.M.M.; Kirkwood, J.M. Re-evaluating the role of dicarbazine in metastatic melanoma: What have we learned in 30 years? Eur. J. Cancer 2004, 40, 1825-1836. 
71. Kölmel, D.K.; Jung, N.; Bräse, S. Azides—Diazonium ions-Triazenes: Versatile nitrogen-rich functional groups. Aust. J. Chem. 2014, 67, 328-336.

72. Kesting, W. Über Cyanurphosphinimines und über pyrogene Spaltungsversuche an Äthyl- und Methylester der normalen Cyanursäure. J. Prakt. Chem. 1923, 105, 242-250.

73. Chapyshev, S.V.; Ushakov, E.N.; Chernyak, A.V. ${ }^{15} \mathrm{~N}-\mathrm{NMR}$ spectra and reactivity of 2,4,6-triazidopyridines, 2,4,6-triazidopyrimidine and 2,4,6-triazido-s-triazine. Magn. Reson. Chem. 2013, 51, 562-568.

74. Klapötke, T.M.; Rienacker, C.M. Drop hammer test investigations on some inorganic and organic azides. Propellants Explos. Pyrotech. 2001, 26, 43-47.

75. Huynh, M.H.; Hiskey, M.; Pollard, C.; Montoya, D.; Hartline, E.; Gilardi, R. 4,4',6,6'-Tetrasubstituted hydrazo- and azo-1,3,5-triazines. J. Energ. Mater. 2004, 22, 217-229.

76. Miller, D.R.; Swenson, D.C.; Gillan, E.G. Synthesis and structure of 2,5,8-triazido-s-heptazine: An energetic and luminescent precursor to nitrogen-rich carbon nitrides. J. Am. Chem. Soc. 2004, $126,5372-5373$.

77. Huynh, M.H.; Hiskey, M.; Hartline, E.; Montoya, D.; Gilardi, R. Polyazido high-nitrogen compounds: Hydrazo- and azo-1,3,5-triazine. Angew. Chem. Int. Ed. 2004, 43, 4924-4928.

78. Ye, C.; Gao, H.; Boatz, J.A.; Drake, G.W.; Twamley, B.; Shreeve J.M. Polyazidopyrimidines: High-energy compounds and precursors to carbon nanotubes. Angew. Chem. Int. Ed. 2006, 45, $7262-7265$.

79. Klapötke, T.M. Chemistry of High-Energy Materials; Walter de Gruyter: Berlin, Germany, 2011; pp. 135-140.

80. Matyáš, R.; Pachman, J. Primary Explosives; Springer Science \& Business Media: Berlin, Germany, 2013; pp. 71-130.

81. Moriarty, R.M.; Rahman, M.; King, G.J. Organic nitrenes in single crystals. Observation of hyperfine structure in the E.S.R. (electron spin resonance). J. Am. Chem. Soc. 1966, 88, 842-843.

82. Nakai, T.; Sato, K.; Shiomi, D.; Takui, T.; Itoh, K.; Kozaki, M.; Okada, K. High-spin nitrenes with s-triazine skeleton. Mol. Cryst. Liq. Cryst. 1999, 334, 157-166.

83. Banks, R.E.; Prakash, A.; Venayak, N.D. Studies in azide chemistry. Part IX. Investigations involving fluorinated azidopyrimidines and 4-azido-3-chloro-2,5,6-trifluoropyridine. J. Fluor. Chem. 1980, 16, 325-338.

84. Pochiniok, A.V.; Sharykina, N.I.; Bakhtiarova, T.A. Antitumor activity of 2,4,6-triazidopyrimidine. Fiziol. Akt. Veshchestva 1990, 22, 76-78.

85. Pochinok, A.V.; Smirnov, V.A.; Brichkin, S.B.; Pochinok, V.Y.; Avramenko, L.F.; Grigorenko, T.F. Photolysis of azido derivatives of pyrimidine. Khim. Vys. Energ. 1982, 16, 151-154.

86. Cernicharo, J.; Guelin, M.; Pardo, J.R. Detection of the linear radical $\mathrm{HC}_{4} \mathrm{~N}$ in IRC +10216 . Astrophys. J. Lett. 2004, 615, L145, doi:10.1086/426439.

87. Allan, R.D.; Greenwood, J.R.; Hambley, T.W.; Hanrahan, J.R.; Hibbs, D.E.; Itani, S.; Tran, H.W.; Turner, P. Studies on pyridazine azide cyclisation reactions. Org. Biomol. Chem. 2004, 2, 1782-1788.

88. Moshchitskii, S.D.; Zeikan, A.A.; Pavlenko, A.F.; Kukhar, V.P. Synthesis and reactions of azidopolybromopyridines. Chem. Heterocycl. Compd. 1979, 15, 1197-1200. 
89. Chapyshev, S.V.; Chernyak, A.V.; Yakushchenko, I.K. Chemoselective Staudinger-phosphite reaction on the azido-groups of 2,4,6-triazido-3,5-dibromopyridine. J. Heterocycl. Chem. 2015, doi:10.1002/jhet2339.

90. Chapyshev, S.V. Synthesis and regioselective cycloaddition reactions of 2,4,6-triazido-3,5dichloropyridine. Mendeleev Commun. 1999, 9, 164-166.

91. Chapyshev, S.V.; Bergstrasser, U.; Regitz, M. Effect of electronic factors on 1,3-dipolar cycloaddition of 2,4,6-triazidopyridines to tert-butylphosphaacetylene. Chem. Heterocycl. Compd. 1996, 32, 59-63.

92. Mikhailov, Yu. M.; Chapyshev, S.V.; Nedel'ko, V.V. Synthesis, thermal stability, heats of formation and explosive properties of cyano-substituted derivatives of di-, tri- and tetraazidopyridines. Russ. Chem. Bull. 2009, 58, 2097-2102.

93. Chapyshev, S.V.; Ibata, T. Synthesis of highly substituted pyridines through nucleophilic substitution of tetrachloro-3-cyanopyridine. Heterocycles 1993, 36, 2185-2190.

94. Chapyshev, S.V. Synthesis and regioselective cycloaddition of 2,4,6-triazido-3-chloro-5cyanopyridine with norbornene. Chem. Heterocycl. Compd. 1993, 29, 1426-1427.

95. Chapyshev, S.V.; Korchagin, D.V.; Shilov, G.V.; Aldoshin, S.M. Synthesis and structure of asymmetric 2,4,6-triazidopyridines. Chem. Heterocycl. Compd. 2011, 47, 817-825.

96. Chapyshev, S.V.; Chernyak, A.V. Synthesis of 2,4,6-triazidopyridine and its 3,5-diiodo derivative. Synthesis 2012, 44, 3158-3160.

97. Chapyshev, S.V. Synthesis of 2,4,6-triazido-3,5-difluoropyridine. Chem. Heterocycl. Compd. 1999, 35,632 .

98. Chapyshev, S.V. Synthesis, thermolysis, and mass-spectrometry of perfluorinated di- and triazidopyridines. Chem. Heterocycl. Compd. 2001, 37, 968-975.

99. Chapyshev, S.V. Di- and triazidation of 3-chlorotetrafluoropyridine. J. Fluor. Chem. 2011, 132, 991-994.

100. Finke, C.; Grote, D.; Seidel, R.W.; Chapyshev, S.V.; Sander, W. Matrix isolation and IR spectroscopic characterization of 3,5-difluoropyridyl-2,4,6-trinitrene. J. Phys. Org. Chem. 2012, 25, 486-492.

101. Ganin, Y.V.; Chapyshev, S.V. Russian Academy of Sciences, Chernohgolovka, Russian Federation. Unpublished work, 2015.

102. Kuzina, S.I.; Mikhailov, A.I.; Chapyshev, S.V.; Korchagin, D.V.; Shilov, G.V.; Aldoshin, S.M. Properties of quintet dinitrenes in 2,4,6-triazido-3,5-dichloropyridine crystals. Russ. J. Phys. Chem. A 2008, 82, 1870-1877.

103. Kuzina, S.I.; Korchagin, D.V.; Shilov, G.V.; Chapyshev, S.V.; Mikhailov, A.I.; Aldoshin S.M. Generation of quintet dinitrenes by low-temperature radiolysis of crystalline 2,4,6-triazido-3,5dicyanopyridine. Dokl. Phys. Chem. 2008, 418, 7-12.

104. Aldoshin, S.M.; Korchagin, D.V.; Bozhenko, K.V.; Shilov, G.V.; Chapyshev, S.V. A study of molecular and crystalline structure of 2,4,6-triazido-3-chloro-5-trifluoromethylpyridine and the rotation barrier of the $\gamma$-azido group around the C-N bond. Bull. Russ. Acad. Sci. Phys. 2008, 72, 1556-1561.

105. Gronowitz, S.; Zanirato, P. Preparation, reactivity, NMR properties and semiempirical calculations of 2-azido- and 3-azido-selenophene. J. Chem. Soc. Perkin Trans. 1994, 2, 1815-1819.

106. Budyka, M.F.; Zyubina, T.S. Theoretical investigation of the azido group dissociation in aromatic azides. J. Mol. Struct. (Theochem) 1997, 419, 191-199. 
107. Alajarin, M.; Conesa, C.; Rzepa, H.S. Ab initio SCF-MO study of the Staudinger phosphorylation reaction between a phosphane and an azide to form phosphazene. J. Chem. Soc. Perkin Trans. 2 1999, 1811-1814, doi:10.1039/A904474D.

108. Chapyshev, S.V. Selective derivatization of 2,4,6-triazidopyridines by the Staudinger reaction. Mendeleev Commun. 1999, 9, 166-167.

109. Chapyshev, S.V.; Platz, M.S. Selective reduction of the azido groups of 2,4,6-triazidopyridines. Mendeleev Commun. 2001, 11, 56-57.

110. Chapyshev, S.V.; Anisimov, V.M. Stereo- and regioselective cycloaddition of norbornene to 2,4,6-triazidopyridines. Chem. Heterocycl. Compd. 1997, 33, 1315-1325.

111. Chapyshev, S.V. Regioselective and regiospecific cycloaddition of acetylenes to 2,4,6-triazidopyridines. Chem. Heterocycl. Compd. 2000, 36, 1289-1299.

112. Chapyshev, S.V.; Bergstrasser, U.; Regitz, M. 1,3-Dipolar tris-cycloaddition of tert-butylphosphaacetylene to 2,4,6-triazido-3-chloro-5-cyanopyridine. Russ. Chem. Bull. 1996, 45, 242-243.

113. Chapyshev, S.V.; Anisimov, V.M. Quantum-chemical study of the nature of regioselectivity in reactions of 2,4,6-triazidopyridines with tert-butylphosphaacetylene. Chem. Heterocycl. Compd. 1997, 33, 587-596.

114. Chapyshev, S.V. Regioselective cycloaddition of the dimethyl ester of acetylenedicarboxylic acid to 2,4,6-triazidopyridines. Chem. Heterocycl. Compd. 2001, 37, 861-866.

115. Chapyshev, S.V. Nucleophilic replacement of the azido groups by amines in 2,4,6-triazido-3chloro-5-cyanopyridine. Mendeleev Commun. 2007, 17, 287-288

116. Chapyshev, S.V. Selective thermolysis of the azido groups of 2,4,6-triazidopyridines. Chem. Heterocycl. Compd. 2003, 39, 83-86.

117. Chapyshev, S.V.; Walton, R.; Lahti, P.M. Orbital control in the selective photolysis of the azido groups of 2,4,6-triazidopyridines. Mendeleev Commun. 2000, 10, 187-188.

118. Wetner, W., Jr. Magnetic Atoms and Molecules; Dover Publications: New York, NY, USA, 1989; p. 294.

119. Chapyshev, S.V.; Korchagin, D.V.; Neuhaus, P.; Costa, P.; Sander, W. Russian Academy of Sciences, Chernohgolovka, Russian Federation. Unpublished work, 2015.

120. Sugisaki, K.; Toyota, K.; Sato, K.; Shiomi, D.; Kitagawa, M.; Takui, T. An ab initio MO study of heavy atom effects on the zero-field splitting tensors of high-spin nitrenes: How the spin-orbit contributions are affected. Phys. Chem. Chem. Phys. 2014, 16, 9171-9181.

121. Turek, O. 2,4,6-Trinitro-1,3,5-tristriazobenzene, a new explosive for detonators. Chim. Ind. 1931, 26, 781-794.

122. Bailey, A.S.; Case, J.R. 4,6-Dinitrobenzofuroxan, nitrobenzodifuroxan, and benzotrifuroxan. A new series of complex-forming reagents for aromatic hydrocarbons. Tetrahydron 1958, 3, 113-131.

123. Adam, D.; Holl, G.; Klapötke, T.M. Nitrophenyl azides: A combined experimental and theoretical study. Heteroat. Chem. 1999, 10, 548-553.

124. Adam, D.; Karaghiosoff, K.; Klapötke, T.M.; Holl, G.; Kaiser, M. Triazidotrinitro benzene: 1,3,5-( $\left.\mathrm{N}_{3}\right)_{3}-2,4,6-\left(\mathrm{NO}_{2}\right)_{3} \mathrm{C}_{6}$. Propellants Explos. Pyrotech. 2002, 27, 7-11.

125. Namba, K.; Yamashita, T. Nitroazidobenzenes. I. Synthesis of nitroazidobenzenes from nitrochlorobenzenes and sodium azide. Kogyo Kayaku Kyokaishi 1958, 19, 86-89. 
126. Bailey, A.S. Improvement in the preparation of benzotrifuroxan-Further examples of complex formation by this reagent. J. Chem. Soc. 1960, 4710-4712.

127. Wallenfels, K.; Witzler, F.; Friedrich, K. 1,3,5-Trichlor-2,4,6-tricyan-benzol und 1,3,5-trifluor2,4,6-tricyan-benzol. Tetrahedron 1967, 23, 1845-1855.

128. Becker, M.; Voss, K.; Villenger, A.; Schulz, A. An efficient route to 1,3,5-triazido-2,4,6tricyanobenzene. Z. Naturforsh. 2012, 67b, 643-649.

129. Boiko, V.N.; Gogoman, I.V.; Shchupak, G.M.; Yagupol'skii, L.M. Nucleophilic substitution in aromatic compounds with fluorine-containing substituents. X. Reactions of 2,4,6-trichloro- and 2,6-dichloro-3,5-bis[(trifluoromethyl)sulfonyl]nitrobenzenes with nucleophiles. Zh. Org. Khim. 1987, 23, 2586-2591.

130. Chapyshev, S.V.; Chernyak, A.V. Triazidation of 2,4,6-trifluorobenzenes. J. Fluorine Chem. 2013, 156, 303-306.

131. Breslow, D.S.; Marcantonio, A.F. Polyazide Crosslinking Agents. U.S. Patent 3297674, 10 January 1967.

132. Kim, H.J.; Lee, W.S. Anion Receptors, and Electrolyte Using the Same. WO Patent 2007126262 , 8 November 2007.

133. Juriček, M. Triazole Materials: Towards Extending Aromaticity. Ph.D. Thesis, Radboud University, Nijmegen, The Netherlands, 2011; Chapter 5, pp. 114-139.

134. Chapyshev, S.V. Synthesis of 2,4,6-Triazidotoluene for Use as Photoaffinic and Crosslinking Agent. RU Patent 2430080, 27 September 2011.

135. Sorm, F. The preparation of tetraazido-1,4-benzoquinone. Chem. Obz. 1939, 14, 37-39.

136. Marburg, S.; Grieco, P.A. Reaction of cyclic anhydrides with sodium azide in polar aprotic media. Tetrahedron Lett. 1966, 1303-1309.

137. Pannell, C.D. Pyridyl azides and their Derivatives. U.S. Patent 3773774, 20 November 1973.

138. Pannell, C.D. Pyridyl Azides and Derivatives. U.S. Patent 3883542, 13 May 1975.

139. Nedel'ko, V.V.; Korsunskii, B.L.; Larikova, T.S.; Mikhailov, Yu. M.; Chapyshev, S.V.; Chukanov, N.V. The thermal decomposition of azidopyridines. Russ. J. Phys. Chem. B 2011, 5, 244-249.

140. Morse, J.G.; Kuhn, L.P. The Reaction of Hexafluorobenzene with Sodium Azide; Defense Technical Information Center: Fort Belvoir, USA, 1970; pp. 1-20.

141. Liu, X.F.; Xu, W.G.; Lu, S.X. DFT theoretical study on nitrogen-rich compounds $\mathrm{C}_{6} \mathrm{H}_{(6-n)}\left(\mathrm{N}_{3}\right)_{n}$ (n=1-6). Gaodeng Xuexiao Huaxue Xuebao 2009, 30, 1406-1409.

142. Du, H.; Xu, X.; Liu, X.; Wang, F.; Zhang, J.; Gong, X. Theoretical studies on the nitro and azido derivatives of benzene. Хuaxue Xuebao 2011, 69, 269-276.

143. Du, H.C.; Wang, Y. The first-principle study on the crystal structures of azido derivatives of benzene. J. Energ. Mater. 2014, 32, 162-171.

(C) 2015 by the authors; licensee MDPI, Basel, Switzerland. This article is an open access article distributed under the terms and conditions of the Creative Commons Attribution license (http://creativecommons.org/licenses/by/4.0/). 